\title{
El narcotráfico en Colombia visto desde una cabina de vuelo
}

Coronel (RA) David Barrero-Barrero

\begin{abstract}
"Seguramente que si hay una máxima militar cuyo valor es universal, es el presionar fuerte hasta derrotar al enemigo"
\end{abstract}

Coronel T.E. Lawrence, 1935

\section{Introducción}

El narcotráfico es, sin duda alguna, uno de los mayores problemas que enfrenta Colombia y sus efectos no se limitan a las tasas de crimen, también este genera repercusiones en la economía, la sociedad, la política y la cultura. La Fuerza Aérea Colombiana (FAC), desde la década de 1970 ha trabajado y se ha adaptado constantemente para hacerle frente a esta amenaza multidimensional. En este sentido, el propósito del presente capítulo es realizar un recuento histórico desde 1970 hasta principios del siglo XXI de cómo ha evolucionado la FAC en aras de combatir al tráfico aéreo ilegal de estupefacientes y de mantener la soberanía sobre el espacio aéreo colombiano. Cabe destacar la participación del General (RA) Édgar Alfonso Lesmes Abad, el General (RA) Flavio Enrique Ulloa Echeverry y el Mayor General (RA) Juan Carlos Ramírez Mejía, quienes contribuyeron enormemente a reconstruir muchos de los datos históricos aquí presentados, además de dar testimonio del arte y 
la ciencia de la estrategia político-militar en la lucha contra el narcotráfico, así como el empleo exitoso de la institución en el cumplimiento de su misión.

El capítulo está dividido en siete secciones. En la primera, se realiza un análisis del contexto y del origen del problema: desde el tráfico que inició en la alta Guajira hasta la migración de la producción de coca desde Perú y Bolivia a Colombia, pasando por la disolución de los carteles de Cali y Medellín y la guerra de sucesión que esto desencadenó. En la segunda, se describe cómo los carteles del narcotráfico han utilizado a algunos pilotos civiles para sus fines y cómo han amenazado a algunos pilotos de la FAC. En la tercera sección, se demuestra que siempre ha existido una respuesta institucional por parte de la Fuerza Aérea, con todos los retos y limitantes que existían. En la cuarta parte del capítulo, se describe qué ocurrió con los corredores aéreos del narcotráfico del Caribe y del Pacífico. En la quinta, se detalla cuáles son las bases bajo las cuales se fundamentaba la estrategia y la legitimidad en las operaciones desarrolladas por la Fuerza Aérea durante esta época. En los dos últimos apartes del capítulo se presenta información acerca del desarrollo de la cooperación con otros países de la región para afrontar este flagelo y la importancia del comando y control como herramienta fundamental para que el Comandante en jefe de la FAC pueda estar informado y tomar decisiones en tiempo real. Finalmente, se presentan las conclusiones pertinentes.

\section{El Origen del Problema}

Algunos autores refieren la historia de la violencia en Colombia prácticamente desde el descubrimiento de América, cuando los españoles impusieron una nueva forma de vida, un nuevo sistema de creencias y comportamiento, en el marco de la colonización del continente. Otras fuentes hacen referencia a esta a partir de la época de la independencia, la inestabilidad política y las pugnas alrededor de la definición y construcción de un régimen político y los diferentes intentos por consolidar el modelo de un Estado (González, 2006, pp. 35-36). Entretanto, otros investigadores manifiestan que el despertar a la historia violenta de Colombia proviene de la década de 1950 (González, 2014, p. 44), con las diferencias entre liberales y conservadores, que sin duda abrieron uno de los capítulos más violentos para Colombia.

Pero, en lo que respecta al narcotráfico y de acuerdo con las investigaciones del Coronel José Manual Villalobos Barradas (plasmadas en el libro "Historia de las Fuerzas Militares de Colombia"), concretamente, el narcotrá- 
fico en Colombia tiene sus orígenes en 1970 con la producción y el envío de marihuana a los Estados Unidos (1993, p. 336). El primer epicentro de la producción y circulación hacia el exterior según el autor fue La Guajira; un lugar que fue, particularmente, estratégico durante las siguientes décadas para dicho fin. Sin embargo, en los primeros años del siglo XXI, la contundente Estrategia de las Fuerzas Militares (FFMM) y, en especial, la de la Fuerza Aérea Colombiana (FAC), dio un giro a favor de la legalidad del Estado.

En palabras del General (r) Edgar Alfonso Lesmes Abad, excomandante de la FAC (2003-06):

El narcotráfico nos sorprendió en las décadas de 1970 y 1980, especialmente en La Guajira donde aterrizaban aviones de todo tipo para cargar marihuana rumbo a los Estados Unidos. La Fuerza Aérea sobrevolaba la península, donde encontraba pistas, aviones y combustible. La FAC trataba de contrarrestarlas destruyendo pistas, las cuales en el término de unas horas las volvían a arreglar. [Además, debía hacerse el traslado de] aviones viejos a nuestras bases $[\ldots]$ pues estos aviones para los narcotraficantes eran desechables, y el combustible que encontrábamos era destruido. (Entrevista estructurada, diciembre de 2019)

Lo anterior, igualmente lo corrobora el General (RA) Flavio Enrique Ulloa Echeverry (ex segundo comandante y jefe del Estado Mayor Conjunto de las FFMM), por cuanto:

Al finalizar la década de 1970 y al inicio de la década 1980, Colombia se convirtió en un centro importante de producción de marihuana, en regiones como La Guajira y posteriormente los llanos orientales. Aeronaves provenientes de los Estados Unidos utilizaban innumerable cantidad de pistas clandestinas que se construían de una manera rudimentaria y muy rápidamente, en áreas de poco o ningún control estatal. Teniendo en cuenta el poco peso de la marihuana y su volumen, corrientemente usaban aviones de tamańo considerable, como DC-3, DC-4, Curtis C-46 e incluso DC-6 y DC-7; sin embargo, también utilizaba aviones bimotores y monomotores pequeńos.

Cuando el Gobierno Nacional empieza a darse cuenta del auge de este tráfico ilegal, genera los planes para contrarrestarlo. El primero es el Plan Fulminante que se desarrolla en el norte del país en la costa del mar caribe, que incluye los departamentos de La Guajira, Magdalena, Cesar, 
Bolívar, Atlántico, Sucre y Córdoba. Finalizando la década de 1970 la Fuerza Aérea Colombiana crea el Grupo Aéreo del Norte, en el aeropuerto de Barranquilla. La FAC asigna aviones de transporte, combate (T-33) y helicópteros, con el propósito de darle cumplimiento al Plan Fulminante.

(Entrevista estructurada, diciembre de 2019)

Igualmente, el General Ulloa, afirma que, al comienzo de la década de 1980 aparece la cocaína como el nuevo problema que planteaba el narcotráfico. En un comienzo "no era mayormente producida en Colombia; [por el contrario,] la mayoría de los cultivos de coca estaban ubicados en Perú y Bolivia, con una producción marginal en nuestro país" (entrevista estructurada, diciembre de 2019); pero con el transcurrir del tiempo, "Colombia se convierte rápidamente en el trampolín para exportar la cocaína a los Estados unidos" (diciembre de 2019).

El proceso consistía, según el General (RA), en la producción en Bolivia y Perú de la base de coca, que luego era "transportada por avión a nuestro país, donde era procesada para convertirla en clorhidrato de cocaína y, posteriormente, transportarla por el caribe y Centroamérica a los Estados Unidos" (entrevista estructurada, diciembre de 2019).

Precisamente, las décadas de 1980 y 1990 tienen una especial significancia, por la múltiple combinación de las nuevas amenazas como el narcotráfico y sus carteles, la guerrilla, el paramilitarismo, las huelgas (Del Río, 2015, p. 221) y la corrupción en las esferas políticas y económicas del país que, a pesar de haberse venido gestando desde años anteriores, logró consolidarse no solamente en Colombia, sino en el mundo entero, debido a una demanda creciente y a la conformación de estructuras criminales con el poder de transportar hasta por vía aérea, narcóticos gracias a la conectividad de la globalización desviada ${ }^{12}$ (Álvarez \& Zambrano, 2017).

Lo anterior representó para la criminalidad una ventana de oportunidad pata abrirse espacios y consolidarse en al país a través de estructuras ilícitas y criminales, dedicas a la comercialización de la droga con organización y links para sus actividades. Además, la asociación de grupos guerrilleros y paramili-

12 Entendida la globalización desviada como: Redes económicas ilegales transfronterizas que producen, mueven y consumen productos y servicios tan variados como narcóticos, faunas en vías de extinción, mercancías falsificadas, dinero sucio, residuos tóxicos, armas ilícitas, así como seres humanos indocumentados en busca de oportunidades laborales y actividades sexuales poco ortodoxas. Esta amplia y próspera gama de servicios e industrias ilícitas se lleva a cabo en sombras de la economía global formal y lícita, y su rápido crecimiento está desafiando las nociones tradicionales de riqueza, desarrollo y poder (p. 276). 
tares que necesitaban recursos para aumentar su tamaño y capacidad; por lo cual, incorporaron el negocio de las drogas como parte de su infraestructura económica y de apoyo en sus fines y propósitos criminales. Como lo menciona el General (RA) Ulloa:

\begin{abstract}
Las zonas más apetecidas por los carteles de la droga para realizar esta actividad fueron la amazonía, en especial los departamentos de Caquetá y Guaviare (allí se localizaba la famosa pista de Tranquilandia), los llanos orientales, lo departamentos de Meta y Vichada (famosa el área de Vista Hermosa, Rio Manacacías y la Raya en el Vichada), el Magdalena Medio (hacienda Nápoles y otras pistas) y la costa Atlántica. (Entrevista estructurada, diciembre de 2019)
\end{abstract}

Por otra parte, el narcotráfico hoy por hoy, se ha constituido en uno de los mayores problemas que Colombia enfrenta, al punto de llegar a ocupar desprestigiosos primeros lugares en el mundo en producción de cocaína, así como comercialización y exportación de la misma, gracias a "la humanidad del mal" (Morin, 2006, p. 210) que tristemente ha escrito uno los capítulos más vergonzosos para Colombia y que, sin duda alguna, no refleja lo que el país es en realidad.

En lo que respecta a esta historia violenta a partir del narcotráfico en Colombia, la Fuerza Aérea Colombiana ha estado a la par con las demás instituciones de la Fuerza Pública (Ejército, Armada y Policía), trabajando en equipo a pesar de tener ocasionalmente muchas diferencias operacionales, doctrinarias, de liderazgo y hasta intereses en los resultados, pero siempre listas a neutralizar la criminalidad del narcotráfico y los delitos conexos que esto ha generado en el país. En algunos momentos críticos la FAC ha sido reactiva o ha estado adelante de las acciones del narcotráfico, pero siempre presta a luchar contra este delito.

Por otra parte, de la marihuana se sabe y se ha escrito desde hace más de un siglo; sin embargo, el desarrollo en firme del consumo y tráfico de ésta puede asociarse al crecimiento en la demanda en los Estados Unidos, en particular, después de la guerra de Vietnam (1955-75). En este país asiático los cultivos de opio se desarrollaban en sus zonas selváticas desde muchos años antes de iniciarse la guerra. Colombia, por tener unas características similares y una ubicación estratégica en el hemisferio americano, se vio como un productor próspero de la marihuana ante la creciente demanda. Con el incremento del negocio del narcotráfico en el país, el interés de muchos no 
se hizo esperar, hubo en la década de 1980 los llamados "patrones", que se encargaron de iniciar el desafortunado negocio que tanto desprestigio y vidas le ha costado a Colombia (Cuerpo de Generales y Almirantes en Retiro de las Fuerzas Militares, 2002, p. 41).

Pronto, el flagelo de las drogas fomentó la organización de los primeros carteles liderados por individuos que rápidamente montaron estructuras criminales, que más adelante hicieron alianzas con la guerrilla, sectores políticos y crearon vínculos en el exterior, además de crear mecanismos para penetrar algunas instituciones.

Detrás de todo lo anterior, "en 1980, Colombia ya surtía el 80 por ciento del mercado del norte. Al principio utilizaban los canales abiertos por traficantes de marihuana, sus conexiones y rutas, hasta penetrar el mercado norteamericano por el sur de Florida" (Pardo, 2004, p. 572). En lo que respecta a la Fuerza Aérea Colombiana, el Mayor General (r) Juan Carlos Ramírez (Ex Jefe de Estado Mayor Aéreo y Segundo Comandante de esta institución) manifiesta:

Los ańos ochenta fueron de aprendizaje; se operaba con aviones T-33 y T-37 desde Barranquilla, posteriormente CACOM-3, haciendo patrullajes sobre La Guajira buscando interceptar aeronaves que despegaban con marihuana hacia los Estados Unidos. No teníamos radares. La capacidad operacional y de inteligencia era bastante limitadas. Sin embargo, a mediados de los ańos ochenta la Fuerza Aérea de los Estados Unidos (USAF, por sus siglas en inglés), en convenio con la FAC instaló radares tácticos en Palanquero, Leticia y Araracuara.

Esta capacidad totalmente nueva nos permitió descubrir que desde pistas cercanas a Palanquero ${ }^{13}$ estaban despegando aeronaves con cocaína, cuyo valor en el mercado americano era sorprendentemente más alto que el de la marihuana. Por esos días, algunos pilotos de la Fuerza Aérea activos y retirados se prestaron para hacer vuelos de narcotráfico. Algunos consiguieron dinero fácil, otros no lograron sobrevivir en el primer intento. Fue una época muy difícil para el país. (Entrevista estructurada, diciembre de 2019)

13 Tradicionalmente así de llama al Comando Aéreo de Combate No.1 ubicado en Puerto Salgar Cundinamarca. 
Lo anterior sin duda, generaba un inmenso reto institucional para hacer frente al problema que se había gestado en el territorio colombiano, aunque sin duda, para el estado colombiano el reto era quizá mayor: combatir en todos los frentes el mismo problema.

De hecho, desde aquella época ya se presentaban ciertas limitaciones estratégicas, que en palabras del señor General (RA) Ulloa, las agrupa y analiza desde los aspectos político, militar y operacional de la siguiente manera:

En lo político:

1. La falta de leyes y normas que permitieran combatir el fenómeno nuevo del narcotráfico.

2. La falta de entendimiento de la sociedad sobre este fenómeno criminal.

3. La falta de políticas de gobierno consistentes. Por ejemplo, el estatuto de seguridad es el primer documento que da instrucciones, de este se deriva el Plan Fulminante.

4. No existía conciencia en los países, incluyendo a Estados Unidos, del crecimiento acelerado del narcotráfico. Por lo tanto, las medidas eran insuficientes para controlarlo.

En lo militar:

1. Falta de definición de una estrategia para combatir el narcotráfico.

2. Limitación en la cobertura de las comunicaciones.

3. Aunque el plan Fulminante fue de alguna manera un plan conjunto, la organización era todavía muy incipiente.

4. Los esfuerzos de las diferentes fuerzas eran aislados

En lo operacional:

1. La Fuerza Aérea carecía de una organización apropiada para hacerle frente al fenómeno, los esfuerzos eran aislados y no se había establecido una doctrina para operar adecuadamente.

2. Los medios aéreos eran insuficientes.

3. Falta de un sistema de defensa aérea y de vigilancia del espacio aéreo. (Para esa época solo existía el radar de Bogotá y posteriormente el de Barranquilla)

4. Falta de un sistema de Comando y Control Centralizado.

5. No existían medios de coordinación con la Fuerza Aérea de los Estados Unidos para desarrollar operaciones combinadas. 
6. La operación nocturna era casi que inexistente.

7. La coordinación con la Aerocivil era muy precaria.

8. No existía suficiente información de inteligencia. (Entrevista estructurada, diciembre de 2019)

Por un lado, en la década de 1990, los carteles de narcotráfico y las agrupaciones guerrilleras que también lo usaban como fuente de financiación como las autodenominadas Fuerzas Armadas Revolucionarias de Colombia (Farc), ya habían sufrido la transformación estratégica necesaria para su negocio, de acuerdo con sus planes y las oportunidades criminales que les ofrecía el tráfico ilícito de las drogas.

Por otra parte, comenzaba a vivirse la decadencia de los partidos tradicionales y se abrían diferentes rutas cardinales para participar en un nuevo escenario político (Del Río, 2015, p. 435), pero ahora más polarizado. También esta época se caracterizó por los acercamientos y diálogos de paz con el Movimiento 19 de abril (M-19), el Partido Revolucionario de los Trabajadores (Prt), el Ejército Popular de Liberación (Epl) y el Quintín Lame. Además, la llamada "séptima papeleta" ${ }^{14}$ logró la instalación de la Asamblea Nacional Constituyente con más de dos millones de votos, la cual fue convocada con el fin de promulgar la nueva Constitución Política de Colombia (1991).

En lo que respecta al negocio de la coca y sus similares, dados los altos ingresos que genera, se han constituido organizaciones criminales y terroristas en cuyas fuentes de financiamiento, además del narcotráfico, están la extorsión, el secuestro y la minería ilegal, por citar algunas de las muchas formas de lucro económico de la convergencia ilícita.

Adicionalmente, "el gran salto que dieron las Farc en el terreno militar se dio a mediados de la década de 1990, cuando Colombia se convirtió en el primer productor de hoja de coca del planeta" (Pardo, 2004, p. 531), lo que fue fundamental para sus planes, en un momento crítico para el país.

Entretanto, las FFMM, incluida la Fuerza Aérea Colombiana, llegaron a encontrarse frente a varios escenarios complejos por la rapidez de la mutación de la situación geopolítica, por lo que era necesario direccionar varios planes para contener las diferentes situaciones que se estaban presentando.

La inteligencia global para combatir las amenazas multidimensionales (OEA, 2003), en las dos últimas décadas del siglo XX, no lograron adaptarse

14 La Séptima papeleta fue un grupo estudiantil que logró en las elecciones de 1989 impulsar la Nueva Constituyente. 
a la velocidad con la que ocurrieron los cambios posteriores a la caída del muro de Berlín y la nueva globalización que abría un nuevo escenario para el mundo.

Las amenazas tradicionales, como las guerras entre los Estados, y en el caso colombiano las tensiones en las relaciones con Venezuela obligaban a la necesidad de un fortalecimiento de las capacidades externas de los dos países con la adquisición de aviones Kfir y F-16, respectivamente. Lo anterior generó una revisión y reestructuración de los planes de guerra, mientras se mantenía la alerta frente al escenario externo. De ahí que, la defensa aérea, como capacidad de la Fuerza Aérea, comenzaba a trabajar no solo en la limitada vigilancia por mantener el control del espacio aéreo en las fronteras, sino también en la supervisión de este frente al incremento progresivo de vuelos ilegales provenientes de países vecinos que también producían cocaína y pasta de coca, así como los vuelos y movimientos ilegales internos.

Por ello, comenzó a generarse una nueva doctrina de la defensa aérea frente al narcotráfico, con las llamadas trazas ${ }^{15}$ provenientes del sur hacia las áreas de la Amazonía y Orinoquía colombiana, que comenzaron a visualizarse en los radares de la FAC. En respuesta la institución lanzaba aeronaves hacia las posiciones de detección o última aparición en las pantallas de los radares. En algunos casos se encontraban las aeronaves en el aire y se perseguían, en otros, se detectaban en tierra y los protocolos de inutilización no estaban regidos completamente, por lo que las dudas llevaron a la necesidad de la implementación de procedimientos para su neutralización.

Además de lo anterior, comenzó a visualizarse un nuevo escenario en el país con la creación improvisada de campos para aterrizar en diferentes lugares de la geografía por parte de los narcotraficantes. Lo cual generaba un mayor obstáculo porque había una dificultad para su visualización por el alcance de los radares y la limitada información proporcionada a los aviones en la búsqueda.

En otros frentes, también, el Poder Aéreo se había puesto a prueba en operaciones significativas de carácter humanitario como la desarrollada en Armero a raíz de la erupción del Nevado del Ruíz (1985) y, por otra parte,

15 Traza se refiere a la trayectoria de vuelo que una aeronave mostrada en las pantallas de los radares. La diferencia con los vuelos legales es que estos transmiten su información de posición y altura especialmente, mediante equipos a bordo. Los vuelos ilegales mantienen estos equipos apagados por lo cual no transmiten ninguna información y por lo tanto, la detección en radares de estos vuelos permite evidenciar alguna anormalidad que debe evidenciarse o verificarse y que al confirmar que la ejecución de algunos de estos vuelos no se encuentra establecida mediante un plan de vuelo legal con una entidad aeronáutica, se constituye en un vuelo ilegal. 
la década cerraba con las operaciones al Estado Mayor del Bloque Oriental (Embo) y la Operación de Casaverde (1990). A pesar de la fuga de información en esta última, el Estado logró sacar de su santuario a los máximos cabecillas de las Farc y a cientos de hombres y mujeres en armas al servicio de las diferentes estructuras. Sin duda, un paso político a favor del Estado, posterior a los intentos fracasados por alcanzar una solución negociada al conflicto.

Por otra parte, "finalizando la década de 1980 la FAC elabora la primera orden de operaciones para interceptar, obligar a aterrizar o neutralizar aeronaves del narcotráfico", esa orden de operaciones fue, en palabras del Mayor General (r) Ramírez, "audaz" (entrevista estructurada, diciembre de 2019). Debido a lo anterior, y más que evidenciado el compromiso del Estado colombiano y para el caso, representado en la Fuerza Aérea, el propio Ramírez afirma que:

Los americanos le dieron un voto de confianza a la FAC permitiendo que controladores colombianos volaran en sus aeronaves E-3 y P-3. Los protocolos de interceptación estaban mejorando día a día con resultados espectaculares, sorprendiendo a los mandos de la USAF por la calidad en el manejo de comunicaciones y en la interceptación de aeronaves del narcotráfico. La frase "end game” (misión cumplida) para los americanos tenía un valor muy grande y el prestigio de nuestra Fuerza cada día era mejor. De hecho, en toda la historia de las operaciones contra el narcotráfico nuestro personal nunca ha cometido un solo error. (Entrevista estructurada, diciembre de 2019)

Ya en la década de 1990, se continuó con el desarrollo de otras operaciones significativas contra el narcotráfico como la desarrollada en el área del Yarí (Caquetá) a principios de la década, de forma conjunta con el Ejército Nacional y coordinada con la Policía Nacional. Durante esta operación se localizaron y neutralizaron algunos laboratorios y pistas de aterrizaje clandestinas. En el desarrollo de las operaciones, por ejemplo, un AC-47T pudo observar en su fir, como un avión bimotor que, al ser detectado, iniciaba carrera de decolaje en una pista denominada "la Y" solo con uno de sus dos motores a potencia máxima mientras, en la maniobra misma, el "intrépido" 16 piloto encendía el segundo motor que terminó de

16 Se dice intrépido en todo sentido negativo: un piloto al servicio del narcotráfico, despegue con un solo motor puede conllevar a un accidente trágico, prender un motor mientras se está en carrera de decolaje es algo difícil, absurdo, peligroso e irresponsable de hacer. 
arrancar prácticamente en el aire. Ya en vuelo, la nubosidad lo ocultó de la persecución del avión militar.

La consolidación de la Fuerza Pública en las pistas del Yarí, permitió entre otras cosas, visualizar la logística y la infraestructura en tierra que tenían estas organizaciones del narcotráfico. En toda la zona se pudo contar más de veinte campos improvisados para la operación. Algunas instalaciones ofrecían el acondicionamiento básico para recibir y despachar vuelos; además, fue decomisado material de uso de estos delincuentes, como luces improvisadas para la adecuación nocturna de las pistas ilegales, también elementos para realizar algún mantenimiento imprevisto a las aeronaves y lógicamente se decomisaron alcaloides y algunas personas fueron detenidas. Pronto, según el mayor General (r) Ramírez, los resultados comenzaron a verse y cuantificarse, pese a las dificultades tecnológicas de aquella época:

Sin embargo, algo sucedió empezando la década de 1990. Oficiales y suboficiales fueron enviados a los Estados Unidos para hacer curso de radares y controladores de radares. Se estaba creando la Dirección de Defensa Aérea en la Fuerza, de la que podemos decir con orgullo que desde el comienzo nació muy bien. A mediados de 1990 los americanos empiezan a instalar radares en La Guajira, San Andrés, Marandúa, San José del Guaviare, Tres Esquinas y Leticia. Estaba naciendo el Air Bridge Denial Program (ABDP) ${ }^{17}$ cuyo plan de interdicción diseñado por la USAF, apoyada por diferentes agencias de los Estados Unidos, la Fuerza Aérea Colombiana y la Policía Nacional, se convirtió con los años en el ejercicio más exitoso en las operaciones contra el narcotráfico. Por esos días, el 95\% de la cocaína era transportada en aeronaves hacia Centroamérica y los Estados Unidos, saliendo de diferentes lugares de Colombia. (Entrevista estructurada, diciembre de 2019)

17 Air Bridge Denial (Negación del Puente Aéreo). Este tema es tratado en detalle en los capítulos uno y dos de este libro. En resumen, este programa permitió y contribuyó de manera efectiva a consolidar una estrategia de interdicción contra el tráfico ilegal, junto con los Estados Unidos y otros países asociados en la lucha contra el narcotráfico. La versión inicial de este programa fue actualizada en 2003 con el Air Bridge Denial (ABD). La vigencia hasta el día de hoy del programa $\mathrm{ABD}$ ha permitido neutralizar aeronaves del narcotráfico, llevar a la cárcel a mafiosos, pilotos e individuos parte de las estructuras criminales, además de la destrucción de laboratorios clandestinos, fortalecimiento de la doctrina operacional; no sólo de la Fuerza Aérea colombiana sino de las demás fuerzas militares que manera conjunta y coordinada son partícipes de los éxitos, así como de otras fuerzas de países vecinos que se han sumado a la lucha contra el narcotráfico de manera mancomunada solidaria y decida. 
Poco a poco se fueron dando éxitos acordes a las capacidades y limitaciones de la Fuerza Pública, que de alguna manera mostraba la contundencia y la decisión del Estado por frenar el avance del narcotráfico. En este sentido, una de las dificultades, que se añadían a la operación contra los grupos criminales, radicaba en contener la infiltración y penetración de estas estructuras no solo al interior de la política, sino entre las FFMM y de Policía. La estrategia de estos grupos consiste en tratar de llegar a los miembros que conforman estas entidades, para obtener de ellos inteligencia, capacidad de sabotaje y retraso de las operaciones contra sus estructuras y cabecillas.

Por fortuna, al interior de las Fuerzas Militares y, particularmente, de la Fuerza Aérea Colombiana, la contrainteligencia siempre ha intentado estar un paso adelante de las organizaciones criminales. Adicionalmente, las políticas de los comandantes parecen ser efectivas para disuadir la corrupción en esta columna vertebral del Estado. La anticipación en todos los frentes ha permitido detectar a tiempo los posibles casos, tomar acciones y permitir el normal desempeño legítimo de las operaciones contra el narcotráfico.

Retomando la operatividad de la Fuerza Aérea en los diferentes escenarios de seguridad y defensa, uno de los hechos trascendentales ocurrió al comienzo de los noventa, durante las operaciones que se realizaban contra la guerrilla y el narcotráfico. Durante el primero de los intentos golpistas en Venezuela, hubo una alerta por una posible incursión de aeronaves a Colombia, por lo que la Defensa Aérea dobló esfuerzos en la vigilancia del espacio aéreo frente a una posible amenaza externa, mientras seguía atenta a perseguir los vuelos del narcotráfico al interior. En 1992, durante el mencionado intento por derrocar al presidente Carlos Andrés Pérez (1989-93) y debido a la información que se dio a conocer, se generó una alerta para las Fuerzas Militares y principalmente para la FAC.

Los pilotos de los aviones de combate estuvieron preparados para en cinco minutos reaccionar hacia la frontera. La inteligencia hablaba del caso de un Hércules C-130 que mantuvo en alerta a los pilotos de A-37 en Barranquilla, así como los Mirage-5 y Kfir en Palanquero, hasta el punto de estar "amarrados" dentro de las aeronaves por cuanto se desconocía el paradero de la aeronave militar venezolana, que después de un tiempo se supo que había aterrizado en Perú con militares golpistas que habían huido de su país. El avión venezolano, al parecer nunca ingresó al espacio aéreo colombiano: voló por el borde de la frontera, pasó a Brasil y aterrizó en territorio peruano. 
La experiencia en la interceptación de aeronaves sería probada en otra misión real, pero de mayor trascendencia, por cuanto implicaría llegar a una aeronave de otro país y obligarla a retirarse del territorio colombiano u obligarla a aterrizar. Podría entenderse como algo simple de hacer, no obstante, de enormes repercusiones en caso de hostilidad de los aviones vecinos. Para este momento, como parte de la madurez operacional de la institución, ya se había establecido una doctrina operacional y jurídica que entregaba resultados, entre los que se podrían contar esas maniobras para obligar a aterrizar los aviones e incluso la destrucción de éstos, en caso de incumplimiento del protocolo de aquellas consideradas hostiles a la soberanía del territorio colombiano.

El incidente no pasó de una falsa alarma, porque la aeronave venezolana no ingresó al espacio aéreo colombiano y, por ende, los aviones interceptores colombianos tampoco salieron a vuelo. Sin embargo, esta alerta fue significativa en su momento porque demostró el potencial de respuesta del Sistema de Defensa Aérea Nacional; no solo frente a las amenazas externas, sino también hacia las operaciones internas, respecto a las violaciones del espacio aéreo colombiano. De hecho, la interceptación de aeronaves ilegales al servicio del narcotráfico comenzó a ser el día a día de las operaciones de la Fuerza Aérea. Por ello, se necesitaba desplegar estratégicamente los medios aéreos para realizar una defensa efectiva del espacio aéreo colombiano.

Las bases aéreas ubicadas en Barranquilla (Atlántico), Apiay (Meta), Cali (Valle del Cauca), Tres Esquinas (Caquetá) y Marandúa (Vichada), especialmente, se convirtieron en unidades de lanzamiento para las operaciones contra la guerrilla y el narcotráfico. Por su parte, las bases aéreas de Melgar (Tolima) y Rionegro (Antioquia) tuvieron qué desplegar igualmente sus helicópteros a instalaciones militares del Ejército y, desde allí, participar en la movilidad y operaciones contra la guerrilla, permitiendo multiplicar la operatividad, no sólo de la Fuerza Aérea sino de las demás instituciones de la Fuerza Pública.

Estos despliegues de helicópteros, a lo largo del territorio nacional, fueron conocidos como Agrupaciones Aerotácticas (AGAT), ejecutadas por pilotos y tripulantes a bordo de sus aeronaves, quienes a partir de esa época planificaron una descentralización de los medios helicoportados. Ellos han recorrido el territorio nacional, llevando el poder de la Fuerza Aérea y de la institución militar a los campamentos, laboratorios de droga y lugares donde los diferentes grupos armados y narcotraficantes han establecido lugares de retaguardia para la producción de pasta de coca, logística y permanente reorganización criminal. 
El incremento en el número de operaciones exigió la búsqueda de alianzas internacionales, lo que condujo a la creación del Plan Colombia ${ }^{18}$, para el fortalecimiento de las capacidades militares en procura de resultados, no solo en Colombia, sino en el exterior, así como el Air Bridge Denial Program (ABDP) para la interceptación de aeronaves (ver capítulo dos).

Más allá de la tempestiva situación interna de Colombia, las instituciones militares debieron fortalecerse y dar respuesta inmediata; no solamente al narcotráfico y sus carteles, sino también a la toma y ataques a poblaciones, a instalaciones militares y de policía, como las sucedidas en Las Delicias (Putumayo) y la toma de Mitú (capital del departamento de Vaupés).

Durante estos periodos, la Fuerza Aérea contaba con una extraordinaria plataforma de ataque, comando y control, inteligencia y reconocimiento: el AC-47T "Fantasma"19. Un avión reconfigurado: desde el C-47 de transporte a una aeronave multipropósito, especialmente el de ataque. Gracias a la colaboración y participación de los EE. UU. se logró la transformación y modificación de estos equipos a una versión de combate con mira para disparo, equipo de navegación, flir, además de personal capacitado y especializado para operar las 24 horas en misiones de largo alcance y larga duración.

Esto condujo a obtener mejores capacidades nocturnas por las que la institución se volcó en un esfuerzo general, el cual se consolidó unos pocos años después en todos sus escuadrones. En su momento, la operación nocturna, a pesar de ser limitada, podía desarrollarse a través del uso de bengalas para la iluminación de los escenarios donde deberían operar las aeronaves. Por consiguiente, apareció un nuevo concepto doctrinario, el de Controlador Aéreo Avanzado (CAA) ${ }^{20}$ (Fuerza Aérea Colombiana, 2019). Este fue

18 El Plan Colombia era una inversión de 7.5 billones de dólares, entre los gobiernos de los Estados Unidos y Colombia. 3.5 billones era el aporte americano y los 4 millones restantes serán asumidos por Colombia. El plan implicaba la creación de batallones de erradicación de cultivos batallones antinarcóticos reestructuración para afrontar el reto del narcotráfico (Pardo, 2004, p. 656).

19 Las aeronaves militares, tradicionalmente y además de su designación militar, son bautizadas y reconocidas con algún nombre. En el caso de Fantasma, su designación como tal se hizo para resaltar las cualidades que un fantasma posee como aparecer de un momento a otro, causar impresión y generar incertidumbre, especialmente hacia el enemigo. Además, al interior de la institución, volar esta aeronave se convertía en todo un honor por las capacidades que poseía y de las cuales se hacía alarde en el tema de resultados.

20 "Esta operación se enfoca en el control de entrega de armas en apoyo aéreo cercano (CAS). Puede realizarse tanto desde aeronaves de ala fija como de ala rotatoria, pero por su especialización requiere plataformas aptas para la observación del terreno, sistemas de comunicación conjuntos e interoperables y sistemas de marcación de blancos" (Fuerza Aérea Colombiana, 2019, p. 111). 
realizado, inicialmente, por aeronaves como el Fantasma, que disponían de bengalas para iluminar el cielo, dirigir sus propios ataques o los ataques de otras aeronaves y pronto, con la operación nocturna de los helicópteros, se fue incrementando la operatividad institucional.

El concepto del Controlador Aéreo Avanzado (CAA) se desarrolló tanto, que ha hecho todo un arte y ciencia de las operaciones de la FAC, por lo que hoy en día, prácticamente desde cualquier aeronave se puede desempeñar tan importante operación, a través de una disciplinada capacitación académica y un completo entrenamiento de tripulaciones ante la necesidad de avanzar con éxito en las operaciones.

Junto con el CAA las operaciones se extendieron a todo tiempo. Simbología, cartografía, uso de mapas, fraseología, procedimientos de entrada y salida de las áreas objetivo, correlación de información, patrones de disparo, comunicaciones seguras con las otras Fuerzas, seguridad y obediencia a las instrucciones con disciplina, hicieron a la Fuerza Aérea mucho más contundente en todas sus operaciones. Al final, superar la noche fue el resultado de un profesionalismo exitoso de todos los escuadrones. Al llegar a los objetivos, el Fantasma lanzaba una bengala que iluminada el área y a partir de allí, lo que seguía era una serie de instrucciones claras y concretas hasta que los pilotos de los aviones de combate o helicópteros confirmaban el 100\% del objetivo militar a la vista, para actuar con las armas de ser necesario.

Más adelante, otras aeronaves adquirirían la capacidad de iluminar la noche para ejecutar las operaciones y con ello se logró llegar a los campamentos y bases logísticas de la guerrilla y el narcotráfico, permitiendo neutralizar al enemigo, retardar su capacidad operativa y consolidar áreas que se encontraban bajo la influencia del crimen.

La preparación de los pilotos implicó una mayor disponibilidad de tripulaciones para los equipos de vuelo, por lo que fue necesario revisar las tripulaciones requeridas por aeronave en cada Escuadrón, así como el factor de fatiga. Adicionalmente, la sorpresa se tornó en un elemento a favor de la FAC. Al iluminar un objetivo, en el caso del narcotráfico, debajo de ella aparecían las aeronaves ilegales aterrizadas en los campos preparados para la operación del narcotráfico, lo que permitió una mayor eficacia y eficiencia de los medios contra los carteles que pretendían mantener una libertad de acción delictiva continuada en el territorio nacional.

Además, las bengalas no solamente se utilizaban para la iluminación. También se usaban como punto de referencia cuando se lanzaban intencionalmente al terreno y a partir de allí, se daban las instrucciones para realizar 
las maniobras contra la guerrilla o el narcotráfico. Años más tarde, los beneficios de esta experiencia facilitaron la transición al vuelo con visores nocturnos y uso de bengalas $I^{21}$, lo que nuevamente revolucionó la capacidad de la Fuerza Aérea y por consiguiente su efectividad.

Toda la capacidad de la Fuerza Aérea se debió involucrar en las operaciones de contención de la violencia de la década de 1990 y la primera del siglo XXI. Hasta los aviones T-27 “Tucano” y T-37C “Tweet", dedicados al entrenamiento de pilotos de combate y que tenían capacidad de disparo, fueron integrados a las operaciones de ataque también.

Paralelo al esfuerzo del Estado, la década de 1980 concluyó con los asesinatos de diferentes servidores y figuras públicas, como el Ministro de Justicia Rodrigo Lara Bonilla (1984), el director del Espectador Guillermo Cano Isaza (1986) y el Procurador Carlos Mauro Hoyos (1988); la captura y extradición de Carlos Lehder (1987), cofundador del cartel de Medellín; el "Plan Pistola" de Pablo Escobar quien, junto con el grupo de los llamados "extraditables", ofrecía dos millones de pesos de la época por la muerte de un policía colombiano, y el atentado terrorista con carro bomba al edificio del Departamento Administrativo de Seguridad (DAS) que produjo la muerte a 63 personas y dejó unos 600 heridos (1989).

En la década de 1990, a pesar del incremento de la violencia, la fuerza pública había logrado la neutralización de Pablo Escobar (1993); la captura de los hermanos Rodríguez Orejuela (1995), fundadores del cartel de Cali, y la clasificación de grupos guerrilleros como las Farc bajo el rótulo de narcoguerrillas, Lo anterior se dio porque este grupo financiaba sus actividades delictivas con vacunas, "impuestos revolucionarios" como ellos mismos lo mencionaban, y también con recursos provenientes del negocio del narcotráfico. Esto representó un golpe político e internacional a las estructuras criminales de las Farc.

También en esta última década, llegó el equipo de aviones OV-10 "Bronco" para la Fuerza Aérea, lo que implicaba un nuevo incremento de las capacidades de operación de esta institución para enfrentar el conflicto interno y contribuir al mantenimiento del orden interno.

21 Infrarrojo, lo que permite no ser visto por el ojo humano sin el uso de equipos de visión nocturna. 


\section{Los Carteles del Narcotráfico a la Cacería de Miembros de la FAC}

A un Estado como el colombiano, con dificultades de seguridad, se sumaba la problemática de no solo uno, sino de varios carteles del narcotráfico operando en su territorio con un alto grado de poder y una capacidad considerable de acción. En este sentido, el reclutamiento de pilotos con o sin experiencia en aviación, comenzó a evidenciarse en el círculo de aviadores de Colombia.

Pilotos que han sido convencidos u obligados por carteles y grupos terroristas a lo largo de la historia para volar aeronaves robadas, en algunos casos, sin información de antecedentes tecno-mecánicos e inclusive, desconocidas y que jamás han tripulado. De ahí que, varios de ellos hayan perecido en vuelos al servicio de organizaciones criminales; otros, simplemente han desaparecido en las selvas suramericanas, de Centroamérica o en el mar, y quizá, algunos también han quedado en el olvido en alguna fosa común ajusticiados por sus jefes.

La noble profesión del aviador terminó convirtiéndose para algunos, en una tarea criminal al servicio del narcotráfico. Aquellos que vendían su alma, pretendiendo alcanzar fortuna y gloria, pronto encontrarían la realidad de una cárcel sin rejas ni barrotes de la cual, una vez adentro ya no podrían salir jamás, por cuanto es de dominio público que quien ingresa a las filas y la nómina del narcotráfico jamás puede salirse sin que le cueste la vida.

Las estructuras criminales también han tratado de reclutar al interior de la Fuerza Aérea a pilotos para sus operaciones. No obstante, como se mencionó con anterioridad, la inteligencia ha permitido mantener neutralizada esta intención. Aunque se debe reconocer que, dada la cantidad de dinero con la cual cuentan estas organizaciones delincuenciales, varias instituciones públicas han sido infiltradas por los narcotraficantes.

Otra de las amenazas y riesgos para los miembros de la Fuerza Pública radica en la persecución y los intentos de asesinato en su contra. Situaciones en las cuales, pilotos de la FAC que han cumplido con éxito sus misiones, luego han sufrido persecución y atentados. Ese fue el caso del Capitán Raúl Castańeda (q.e.p.d.) quien, unos meses después de participar en las operaciones de Casaverde contra las Farc, fue desaparecido y luego asesinado (1991).

Situaciones como estas, son motivaciones para que la Fuerza Aérea Colombiana continúe con su labor, bajo la convicción de ayudar en la construcción de un país mejor. Lo que si es cierto es que las amenazas y los riesgos que 
enfrenta la FAC en su lucha contra el narcotráfico han obligado a la entidad a adoptar nuevas estrategias, como, por ejemplo, el secreto de las operaciones y un mayor control y supervisión de los miembros de la institución y sus familias a fin de reducir los riesgos a su vida.

\section{Siempre ha Habido Respuesta Institucional}

\section{El Grupo Aéreo del Norte (GANOR) - hoy Comando Aéreo de Combate No. 3 (CACOM-3)}

En los años setenta, la Fuerza Aérea Colombiana contaba con el equipo T-33 "Silver Star", cuya llegada al país (1954) se dio como resultado de su compra a los Estados Unidos. Este equipo prestó un honorable servicio a Colombia que se extendió hasta 1990, cuando salió de servicio (Fuerza Aérea Colombiana, 2019). Además, contaba también con el equipo T-37C "Tweet” que llegó en 1968 para el entrenamiento avanzado de pilotos, pero que poseían capacidad de ataque.

Los T-33, cuya base era el Comando Aéreo de Combate No. 2 con sede en Apiay (Meta), eran destacados para misiones de interceptación de aeronaves ilegales en el Grupo Aéreo del Norte (GANOR) ubicado en el aeropuerto de Barranquilla, hoy en día conocido como Comando Aéreo de Combate No. 3 Base Aérea "MG. Alberto Pauwels Rodríguez"22 (Fuerza Aérea Colombiana, 2019). La jurisdicción de esta base desde ese entonces ha abarcado "la zona continental norte de Colombia, el área insular del Archipiélago de San Andrés y Providencia y las aguas jurisdiccionales del Mar Caribe" (Fuerza Aérea Colombiana, 2019).

De acuerdo con lo anterior y debido a la necesidad de realizar operaciones en el Caribe, el GANOR comenzó a gestarse en la década de 1970, bajo el comando de la Fuerza a cargo del General Alfonso Rodríguez Rubiano. Él comenzó a gestionar el proyecto en 1976, que fue consolidado en 1977 con la Disposición 7077 del Ministerio de Defensa que dio paso al GANOR, cuya inauguración se dio en 1978 (Fuerza Aérea Colombiana, 2019). Lo anterior, gracias a la visión del General Rodríguez, la cual era la de "negar el tráfico aéreo y marítimo de marihuana que procedía desde La Guajira hacia los EE. UU.” (Fuerza Aérea Colombiana, 2019).

También conocido como CACOM-3. 
Adicionalmente, en la misma década, llegaron las dos primeras aeronaves A-37B "Dragonfly" 23, como refuerzo operacional para la FAC a partir de 1978 (Fuerza Aérea Colombiana, 2019). La entrega final se dio hasta 1989, con lo cual se completó una flota total de 30 aeronaves (Fuerza Aérea Colombiana, 2019). A partir de entonces, su servicio se ha extendido hasta la época contemporánea, siendo indudablemente uno de los equipos longevos en la institución, pero de una trayectoria indudablemente prestigiosa, así como lo fue el T-33.

La llegada de los A-37 fue el producto de la necesidad de aumentar la capacidad contra el narcotráfico y las operaciones contra la insurgencia, además de una disuasión externa creíble, en la que estos aviones de alta maniobrabilidad y buena velocidad encajaban muy bien con los planes de defensa nacional. En la estrategia contra el narcotráfico específicamente y por ser bimotor, se adquiría una mayor garantía en seguridad para la operación en el mar (Fuerza Aérea Colombiana, 2019), extendiendo las condiciones de vuelo seguro a todo tiempo.

Ambos equipos, sin duda alguna, han escrito una larga lista de éxitos estratégicos y operacionales para la patria y han sido muchos los pilotos y tripulantes quienes han tenido el honor de haber volado y volar en la actualidad alguno de estos dos aviones de combate.

En la península, el movimiento ilegal del narcotráfico se hacía desde campos no preparados. Diferentes tipos de aeronave llegaban, cargaban y salían hacia los Estados Unidos, principalmente, en diferentes rutas a través de Centroamérica o por el Caribe. Algunas de estas aeronaves como lo relata Villalobos, quedaban accidentadas y abandonadas en diferentes lugares de la península (1993, p. 336), por múltiples circunstancias como: I) las características del terrero inapropiado para la operación de aviones, II) la fragilidad del tren de aterrizaje de muchos de estos aparatos, III) posiblemente la falta de experiencia de los pilotos para operar en estas circunstancias, incluidos vuelos nocturnos, y IV) una logística poco preparada para las eventualidades tecno-mecánicas de los aviones.

Además, muchas veces por el afán de aterrizar cuando se era perseguido por una aeronave del Estado, las condiciones en que se daba esta maniobra no facilitaban hacerlo de manera segura. Era evidente que los pilotos debían realizarlo de la forma más rápida posible para evadir la acción militar. Desde la cabina de los aviones se podía apreciar muchas veces cómo una carrera al

Tradicionalmente han sido conocidos como Los Dragones. 
servicio de la delincuencia en la clandestinidad terminaba en algunos casos en accidente fatal.

Por otra parte, las operaciones contra el narcotráfico desde aquellas épocas requerían de un trabajo en equipo entre la Fuerza Aérea Colombiana y la Armada Nacional, especialmente, en la jurisdicción marítima en toda la costa del Caribe. El área desde La Guajira hasta el Urabá, ha sido también objeto de lucha contra el narcotráfico. Los traficantes de drogas se las han ingeniado para lanzar sus lanchas rápidas por diferentes rutas, por lo que el trabajo en equipo ha sido indispensable en la lucha contra el narcotráfico. Por lo cual, los recursos de la Fuerza Aérea se han puesto al servicio de la Armada para contrarrestar el narcotráfico marítimo y, en otras circunstancias, la Armada ha acompańado a la FAC para cierres, rescates y consolidación de playas, cuando las aeronaves ilegales han llegado a costas o simplemente no han alcanzado estas, quedando accidentadas en el camino. En algunas operaciones también se ha vinculado a la DEA de los Estados Unidos, la cual ha contribuido a la captura de personal vinculado a las mafias de la droga, así como la incautación de los estupefacientes y el material involucrado.

\section{El Grupo Aéreo del Caribe (GACAR)}

En 1981, y poco después del GANOR, se vio la necesidad de constituir una base aérea en la isla de San Andrés. Esta base ayudaría para: I) salvaguardar el espacio aéreo, II) asistir en la protección marítima en el Caribe colombiano, III) hacer frente al narcotráfico y IV) afrontar una posible amenaza proveniente de Nicaragua y su reclamo sobre la soberanía de San Andrés y Providencia. La capacidad de despliegue y lanzamiento de operaciones desde el GACAR, también denominado "Teniente Coronel Benjamín Méndez Rey”, representó el poder de disuasión externo e interno frente a los dos polos de amenaza.

San Andrés ha sido considerado por el narcotráfico como un punto estratégico para lanzar aeronaves y lanchas desde y hacia Colombia. De ahí que, en diferentes oportunidades, el aeropuerto internacional ubicado en esta isla llegó a ser utilizado por la clandestinidad como zona de tránsito de drogas y también para realizar vuelos ilegales, que de un momento a otro llegaban y salían en un silencio de radios, a espaldas de las autoridades aeronáuticas y seguridad aeroportuaria y con la complicidad de otros.

El archipiélago se constituyó, por su ubicación geoestratégica, en punto logístico y de transición entre droga y dólares producto del negocio del narco- 
tráfico. Por otra parte, la penetración de las estructuras criminales promovió el reclutamiento de personal en la isla que se fue vinculando y facilitando sus lanchas al servicio criminal. Muchos de estos individuos provenían de diferentes partes de Colombia buscando instalarse en la isla para sus fines lucrativos en asocio con la mafia.

Pero, con el tiempo, las autoridades pusieron en marcha diferentes planes a fin de contrarrestar el narcotráfico y las estructuras criminales, así como de la contención en el uso de aguas y espacio aéreo. En el caso de la Fuerza Aérea, esta debió activar en plan para blindar a todos sus miembros de la influencia del narcotráfico y las vulnerabilidades de sus consecuencias, generando confianza y seguridad hacia el interior de la institución. Además, los resultados de las operaciones que se desarrollaron de forma autónoma o en conjunto con la Armada, el Ejército y coordinada con la Policía, permitieron garantizar la solidez institucional para reducir el problema.

Hoy por hoy, es evidente que los resultados a través de los años han visto un mayor progreso con respecto a la disminución de la influencia del narcotráfico en el Caribe colombiano; sin embargo, se requiere de constante trabajo y de apoyo de las autoridades de otros países, en pro de consolidar un escenario más seguro y alejado del tráfico ilegal de estupefacientes.

Además, con la instalación de un radar por parte de la Fuerza Aérea, esta institución ha contribuido no solamente a la detección del narcotráfico sino al control aeronáutico civil qué sirve $\mathrm{Al}$ aeropuerto de San Andrés, por lo que la construcción y puesta en funcionamiento de una base aérea ha ayudado en el fortalecimiento operacional de las FFMM en esta región del país.

\section{El Grupo Aéreo del Sur (GASUR) - hoy Comando Aéreo de Combate No. 6 (CACOM-6)}

Esta unidad de combate de la Fuerza Aérea denominada también como base aérea "Capitán Ernesto Esguerra Cubides", es una de las más antiguas; su existencia data de 1933 y fue creada "con el propósito fundamental de conducir operaciones ofensivas de contraguerrilla y control del narcotráfico en el área total de $190.362 \mathrm{~km} 2$ comprendida por los departamentos del Caquetá, Putumayo, Meta y Guaviare" (Fuerza Aérea Colombiana, 2019).

Desde esta base aérea, se han lanzado operaciones de todo tipo como las ejecutadas en la guerra contra Perú (1932-33), así como la ejecución de operaciones contra el terrorismo en Colombia y sus cabecillas. También, esta unidad ha sido fundamental para llevar a cabo, a lo largo de muchos años, 
misiones contra los corredores del narcotráfico que provienen del sur del país u otros corredores hacia el Pacífico colombiano, además de bases campamentarias y laboratorios. En síntesis, el conflicto con Perú permitió la creación de esta base aérea para el desarrollo de las operaciones en un territorio complejo, difícil y con grandes limitaciones de soporte logístico para toda la institución militar, precisamente, por la característica selvática de la zona. Desde allí se realizan operaciones hacia toda la amazonia colombiana.

Cuando el narcotráfico volaba sin mayores dificultades por toda esta región, lo hacía empleando campos de aterrizaje, que fueron descubiertos por la Fuerza Aérea después de labores de inteligencia, vuelos de reconocimiento y un gran esfuerzo de búsqueda. La FAC llegó a los sitios como la pista de Tío Barbas, en el área de Carurú (Vaupés) y Yucinas (Amazonas) entre muchas más; ubicadas en la selva o en territorios de difícil acceso. También en Puerto Gaitán (Meta) y Nueva Antioquia (Vichada) justo en la frontera con Venezuela, donde las distancias a partir de los Comandos Aéreos de Combate No. 2 de Apiay (Villavicencio) y 6 en Tres Esquinas (Caquetá) dificultaban la consolidación de la institución frente a la lucha contra el narcotráfico.

\section{Estrategia de la neutralización y destrucción de pistas}

El paso posterior a la localización del punto de partida de los vuelos ilegales es la neutralización y la interdicción, tanto de los sitios como de las rutas. Frente a la cantidad de pistas y campos de aterrizaje organizados y adecuados por el narcotráfico para sus actividades ilegales, la Fuerza Pública reconoció la necesidad de combatir paralelamente la logística y la infraestructura de las redes criminales.

Una estrategia que se implementó fue la de destruir e inutilizar estos campos de aterrizaje. En algunos casos, las capacidades de la Fuerza Pública no permitían llegar hasta esas pistas clandestinas para consolidarlas, por lo que se planearon alternativas para cumplir los objetivos y las órdenes superiores. De ahí que, la Fuerza Aérea organizó un plan para neutralizar aquellos lugares distantes y lejanos del alcance de las fuerzas estatales, para lo cual hizo uso de armamento especial que permitiera penetrar lo suficiente en el terreno e inutilizarlo definitivamente o, por lo menos, retardar significativamente la operación del narcotráfico desde estos lugares.

Por otra parte, la Dirección Antinarcóticos de la Policía Nacional haría un trabajo similar en tierra, en aquellos campos de aterrizaje en donde se pudiera hacer una consolidación que permitiera de forma segura la destrucción 
de estas pistas ilegales empleadas por el narcotráfico. Este trabajo en equipo permitió en gran parte la neutralización del tráfico aéreo ilegal en Colombia, obligando al narcotráfico a operar fuera del territorio nacional, lo que implicó que el Estado estableciera acuerdos regionales para combatir al narcotráfico.

Además de lo anterior, estas misiones permitieron fortalecer la doctrina institucional, por cuanto era necesario una precisión lo más cercana a la perfección, por los altos costos que representaba el empleo de armamento y horas de vuelo invertidas para tal fin. La entrega de las armas, en estos objetivos requiere mucho entrenamiento previo y hasta la selección de las tripulaciones más experimentadas. Una pista clandestina se atacaba prácticamente sobre el eje de la trayectoria de esta, evitando cualquier influencia como la del viento o cualquier pequeńo error durante el disparo, para evitar que el armamento no cayera en el centro, puesto que el ancho de esas pistas clandestinas podría tener un promedio de cinco metros. A pesar de las dificultades, gracias al gran esfuerzo de la FAC, se logró el objetivo de bloquear poco a poco el uso del territorio colombiano para los vuelos ilegales.

No fueron pocos, por el contrario, fueron muchos los lugares donde se debió interdictar al narcotráfico. Negar el uso del espacio aéreo para el tráfico de pasta de coca hacia el exterior y/o el regreso con dinero, fruto de la entrega en Centroamérica o el Caribe, implicaba atacar la infraestructura y la logística del crimen. Como se mencionó anteriormente, en la medida en que las operaciones fueron exitosas en Colombia, las estructuras criminales fueron abriendo otros escenarios fuera de la frontera colombiana.

Una de las misiones más complejas fue llegar a Yucinas en la Amazonía, en cercanías a la frontera con Brasil, a través del reabastecimiento de combustible en vuelo por parte de los Kfir desde Palanquero (Puerto Salgar, Cundinamarca). En esta tarea se neutralizaron dos pistas ubicadas en ese lugar bajo mínimas condiciones meteorológicas, con lluvia y baja visibilidad, las cuales condujeron a perder el contacto visual entre aviones, obligando a ejecutar la maniobra de ataque a baja altura y con la máxima coordinación de radio posible. El éxito de esta misión, por el tiempo de vuelo realizado y la distancia recorrida para una misión de ataque real, se constituyó en su momento en un récord operacional de la Fuerza Aérea Colombiana (Barrero \& González, 2004). Como la anterior, fueron muchas las operaciones de destrucción de pistas y campos ilegales, en las que la Fuerza Pública invirtió su potencial y capacidades en la guerra contra el narcotráfico; no solamente al sur del país, sino en diferentes lugares del territorio colombiano, en donde la inteligencia marcó los lugares en los cuales el narcotráfico violaba la soberanía nacional. 
Es de resaltar el trabajo en equipo alcanzado al final de la década de 1990 y a comienzos del siglo XXI, puesto que esta capacidad de ataque e integración con la inteligencia permitió incrementar la efectividad en las operaciones. Por ejemplo, este fue el caso en la retoma de la Zona de Distensión en 2002, cuando fueron suspendidos los diálogos de paz con las Farc a raíz de los incumplimientos con lo pactado y de las acciones ilegales del grupo armado en esta región. La suspensión de los diálogos y posterior retoma de la zona de despeje de San Vicente del Caguán constituyó en un tercer golpe político muy contundente en contra de esta organización.

En resumen, se trabajaba, como se ha mencionado, de forma conjunta, coordinada y hasta de manera interagencial y combinada para enfrentar el narcotráfico. Como lo menciona el señor General (r) Lesmes,

[con la información de] inteligencia para destruir laboratorios dedicados al procesamiento de la cocaína en todo el territorio nacional se inició el control del Espacio Aéreo con el uso de los radares militares y civiles y, posteriormente, con los aviones de inteligencia AWACS de los Estados Unidos para evitar que aviones dedicados al transporte de los narcóticos utilizaran nuestro espacio aéreo. (Entrevista estructurada, diciembre de 2019)

\section{El Comando Sur de los Estados Unidos}

Parafraseando al señor Mayor General (r) Juan Carlos Ramírez, Oficiales seleccionados por la propia Fuerza Aérea, bajo ciertos requisitos especiales de liderazgo, mando, proyección institucional y hoja de vida, han sido enviados desde hace más de dos décadas en Comisión a los Estados Unidos como Oficiales de Enlace asignados a la Joint Interagency Task Force South (JIATF-S por sus siglas en inglés) del Southcom o Comando Sur de los Estados Unidos en Key West, Florida, igualmente, Ramírez sostiene que allí, se tiene:

La oportunidad de conocer los enlaces de diferentes agencias de los Estados Unidos como la DEA, el FBI, la Aduana, USAF, el cuerpo de marines (USMC, por sus siglas en inglés), el ejército de este país y la Armada (USN, por sus siglas en inglés), además de oficiales de enlace de casi todos los países latinoamericanos y algunos europeos. (Entrevista estructurada, diciembre de 2019) 
Precisamente, el señor Mayor General (RA) relata su experiencia como representante, no solo de la FAC, sino del Estado colombiano, en una agencia hemisférica en la que varios países tenían los mismos intereses de combatir entre muchos problemas multidimensionales, en especial, el narcotráfico, así como intercambiar inteligencia, entrenamiento y realizar ejercicios multinacionales contra el crimen y el delito:

No puedo decir que me sentía bien en ese cargo porque sabíamos que el problema era Colombia, pero eso hacía más retador mi trabajo. Era el único enlace que tenía permiso para entrar al Centro de Comando y Control (CDOCC) del JIATF-S y de esta manera analizar cómo trabajaban la inteligencia, las comunicaciones, el control y el comando como un solo equipo para producir resultados, en donde los protagonistas eran los controladores colombianos a bordo de las plataformas americanas dirigiendo con precisión milimétrica las aeronaves de la Fuerza Aérea contra los aviones del narcotráfico. Esta fue una oportunidad única y a pesar de saber que el problema por esos días era Colombia, los americanos se admiraban de nuestra capacidad operacional. (Entrevista estructurada, diciembre de 2019)

Por otra parte y de acuerdo con el señor General (RA) Lesmes, excomandante de la FAC, la "alianza con los Estados Unidos [a través del] ABD; [los acuerdos] con países de Centro América para intercambiar información sobre vuelos ilícitos; así como con Perú y Brasil, con quienes se hicieron ejercicios en las fronteras para coordinar interceptaciones de estos vuelos," (2019), representaron un salto operacional de algunas Fuerzas Aéreas del hemisferio, así como de las otras Fuerzas, encargadas de hacer su aporte a la consolidación de la estrategia aérea, además de las agencias de inteligencia. En este sentido, el General Lesmes considera que

Estas alianzas fueron muy efectivas, pues con el trascurso del tiempo se fueron reduciendo las trazas detectadas en el comienzo del siglo y para el año 2006 ya prácticamente las trazas detectadas por todos nuestros medios y los de los Estados Unidos habían desaparecido de nuestro espacio aéreo. (Entrevista estructurada, diciembre de 2019)

Adicionalmente, él menciona que debido a esta estrategia regional y de efectos globales, los vuelos ilegales del narcotráfico se comenzaron "a ver en 
el espacio aéreo venezolano, y en el Pacífico las lanchas go-fast $t^{24}$ y sumergibles, los narcotraficantes cambiaron su modalidad de transporte debido a la efectividad del control del espacio aéreo por parte de la Fuerza Aérea" (2009).

\section{Los Primeros Corredores del Narcotráfico}

\section{Organización criminal}

Para el 2000, las Farc, el autodenominado Ejército de Liberación Nacional (Eln) y los grupos paramilitares estaban organizados y, además de una larga lista de delitos y de acciones terroristas, utilizaban el narcotráfico como una fuente de financiación. Según el libro Esquilando lobos. La dimensión desconocida del conflicto colombiano, escrito por el Cuerpo de Generales en Retiro de las Fuerzas Militares (2002), para aquella época "las Farc contaban con 40 de sus 64 frentes dedicados al narcotráfico; el Eln, con siete de sus 42 unidades, y los paramilitares, [...] con nueve de sus 21 compañías" (2002, p. 38). Con unos ingresos, resultado del narcotráfico, de " $\$ 1.111 .000 \mathrm{mi}-$ llones" (2002, p. 38), el panorama era muy complejo no solamente para la Fuerza Aérea, sino para todo un país que sufriría las acciones terroristas de estos grupos y de los carteles de la droga.

Para ese entonces, los grupos alzados en armas habían pasado de ser cuidadores de cultivos y cobradores de vacunas ${ }^{25}$ en los pasos de tránsito de los lugares de producción a los sitios de embarque y distribución, a ser "empresarios" del narcotráfico. Ellos destinaron estructuras completas a todos los procesos del narcotráfico, desde los cultivos y el procesamiento en laboratorios clandestinos propios, ubicados debajo del follaje de las selvas colombianas,

24 Las conocidas pangas para la pesca tradicional son acondicionadas hasta con motores de alta velocidad y dotadas de GPS, lentes de visión nocturna y comunicación satelital. Las lanchas rápidas, más conocidas en el mundo del narcotráfico como go-fast, fueron puestas al servicio el contrabando del narcotráfico para burlar a las autoridades y reducir rápidamente las distancias en el mar y reducir los tiempos de traspaso de drogas y dinero en el mar. Los dueños de estas embarcaciones al servicio del narcotráfico han sabido dificultar en ocasiones el accionar de las instituciones estatales, como pintar el interior de estas de azul o verde para ser poco detectadas desde el aire, así como cubrir los motores con lonas del mismo color y apagarlos, cuando detectan una aeronave encima, que pueda descubrirlos con medios ópticos o detectores de calor.

25 Se hace referencia al llamado por el terrorismo "impuesto revolucionario", que consistía en un cobro extorsivo sin importar a quien hacerlo, pero qué implicaba el recaudar fondos para el sostenimiento de las estructuras criminales. 
peruanas y bolivianos principalmente, hasta la negociación y el establecimiento de alianzas con carteles en exterior. Cabe recordar algunas de esas estructuras como el Frente 16 de las Farc, cuyo cabecilla alias "Negro Acasio" se hizo famoso por ser quien manejaba el narcotráfico de este grupo en Vichada y Guainía, especialmente. Además, entre Nariño, Putumayo y Cauca, se repartían el trabajo de cultivar, producir y exportar, los frentes 2, 48, 29, 32, 60 y 64, y en el Caribe los frentes 59, 41 y 19.

Entrando en el siglo XXI, los corredores del narcotráfico que tradicionalmente han existido son los del Pacífico y el Caribe. Este último, alimentado especialmente por los otros corredores que provenían del sur de Colombia hacia las selvas y que conectan con otros corredores hacia el norte colombiano o por el norte de Venezuela. Este tránsito pudo ser combatido por las fuerzas del Estado al punto de eliminarlo del territorio nacional, logrando con esto, que las redes del narcotráfico migraran su corredor por el oriente del país. En ambos, la delincuencia de los carteles lanzaba sus vuelos con aeronaves de todo tipo; tanto bimotores como monomotores, legales o ilegales, robadas o provenientes de otros países, con o sin matrícula de alguna nacionalidad, por nombrar tan solo algunas características del origen de una capacidad aérea que han tratado de mantener. De lo anterior y según el señor Mayor General (RA) Ramírez, se puede mencionar que normalmente "la Fuerza Aérea interceptaba aeronaves tipo C-206, B-80, C-90 y Turbocomander con aeronaves A-37. En ocasiones participaban los AC-47 cuando el objetivo era interceptado en tierra" (Entrevista estructurada, diciembre de 2019).

\section{El corredor del Pacífico}

En el Occidente colombiano, las pistas clandestinas o campos preparados para despegue y aterrizaje ilegal fueron acondicionadas desde el Urabá hasta Nariño, siendo Chocó y el Bajo Cauca quizá el área de mayor operación clandestina. En las playas chocoanas las pistas eran poco detectables desde el aire, por su adecuación propia para una operación simple o por el camuflaje con vegetación. Además, poco a poco el mismo narcotráfico, fue acondicionando sus operaciones nocturnas con iluminación instalada a pocos minutos de la llegada de los aviones.

Esta región de Colombia, a pesar de tener menor influencia, si ha tenido otras características que el narcotráfico ha explotado en su beneficio. Además de los vuelos ilegales, la fabricación de semisumergibles ha sido una de esas capacidades que han desarrollado traficantes de sustancias psicotrópicas. 
El despliegue operacional de la FAC desde la base aérea de Cali, por ejemplo, ha permitido de manera conjunta con la Armada, el Ejército y la Policía, desarrollar operaciones a partir de la unificación de una inteligencia de combate que ha logrado neutralizar la fabricación de estas naves, así como su interdicción en el mar en colaboración, en algunas operaciones, con los Estados Unidos.

\section{El corredor del Caribe}

La misma capacidad para la distribución y, en general, la instalación de puntos estratégicos para el negocio de las drogas se dio para el Caribe en donde se acondicionaron pistas para de llegada y salida de aeronaves. Las características del terreno facilitaban la adecuación de éstas, además, la lejanía con respecto a unidades militares favorecía el proceso; así la alta Guajira se conectaba con los Llanos Orientales y la Amazonía. En la península, hubo varias pistas cuyos nombres eran reconocidos por la Fuerza Aérea a la hora de lanzar las aeronaves para la interceptación. La Internacional o Las Paralelas eran las más comunes para la operación rápida de los carteles, cuya logística para el arribo y despacho de sus aviones llegó a ser más veloz que la capacidad de reacción de la Fuerza Pública, debido a que las bases de lanzamiento de la Fuerza Aérea estaban ubicadas a una distancia considerable.

Por un lado, en la década de 1990 y los primeros años del nuevo siglo, y a pesar de poseer aeronaves rápidas como los A-37, la distancia desde Barranquilla hasta el extremo norte de La Guajira implicaba mucho tiempo de vuelo y poca capacidad de sostenimiento y hasta persecución de las aeronaves ilícitas. Una situación que poco a poco fue mejorando con nuevas estrategias, inteligencia y alianzas internacionales que se mencionaran más adelante. Para dicho momento, solo se contaba con un radar que cumplía la misión de hacer seguimiento y lanzar las aeronaves, sin mayores garantías de éxito. La inteligencia estaba reorientando sus esfuerzos a las nuevas amenazas de la seguridad multidimensional (OEA, 2003); un escenario, en general, nuevo para la política, la estrategia, la inteligencia y la táctica, puesto que las amenazas tradicionales (OEA, 2003) siempre apuntaron a los objetivos externos del país principalmente, a pesar de que el combate contra los grupos guerrilleros era otro frente de contención interno.

Por otra parte, en el oriente y en la selva colombiana el narcotráfico desplegó capacidades de operación fuera del rango de alcance de la detección de los radares y menos aún de la capacidad y alcance de los aviones. Pistas 
como la denominada Tío Barbas, al occidente de la ciudad de Mitú (Vaupés), representó por mucho tiempo un lugar estratégico para la llegada y salida de aeronaves al servicio del narcotráfico sin mayores complicaciones de detección o persecución de la Fuerza Aérea. Lo anterior ocurrió debido, en principio, a la distancia y el alcance de los aviones y por su logística de despacho rápido, lo que la convertía sin duda en un punto de movimiento aéreo ilegal de narcóticos y dólares.

\section{La Ejecución de las Operaciones desde la Cabina}

Durante las décadas de 1980 y 1990, las unidades aéreas recibían la información y procedían a lanzar los aviones para complementar la búsqueda de una aeronave en el aire, la cual según el estimado de personal de radares se encontraría en un área general que bien podría tener un radio de cualquier cantidad de millas. Poco a poco la experiencia, el entrenamiento, el cálculo de mejores estimados y la propia inteligencia, fueron recortando tiempos y distancias para interceptar las aeronaves qué violaban el espacio aéreo nacional.

Los procedimientos para estas misiones de interceptación han sido establecidos por la Organización de Aviación Civil Internacional (OACI), los cuales fueron desde un principio la normatividad legal bajo la cual se interceptaban aeronaves ilícitas y sobre la base de ésta se llegaba inclusive al derribo. En muchas ocasiones, las aeronaves civiles intentaban burlar la maniobrabilidad de los aviones, procurando volar lento y a ras de piso, pero, terminaban accidentadas en las selvas a consecuencia de las maniobras que realizaban, como se dijo, a baja altura y velocidad.

Lo característico era intentar alejar a los interceptores de las bases de lanzamiento, afectando su autonomía de vuelo y alcance para continuar la persecución o buscar la manera de ocasionar un accidente por volar a baja altura. En interceptaciones sobre el mar sucedía lo mismo; de hecho, esto beneficiaba al infractor, cuando las autorizaciones de disparo para el derribo demoraban en llegar a través de la frecuencia de radio, por lo que las aeronaves ilegales optaban por regresar y/o alejarse de los aeropuertos en donde pudieran ser obligadas a aterrizar, además de dificultar los tiempos de vuelo de los interceptores.

Otra forma de obstaculizar la acción legítima de la Fuerza Aérea consistía en permanecer o mantenerse 200 millas fuera la costa, lo que hacía 
jurisdiccionalmente complicado perseguirlos. Lo anterior condujo a nuevos procedimientos y acuerdos con otros países para sobrevuelos y entrega a esos países de las trazas para su autónoma operación, así como el intercambio de inteligencia y seguimiento del accionar delictivo en sus lugares de operación.

\section{El Problema de Disparar}

Parte de la misión de una Fuerza Aérea es mantener en nombre del Estado la "soberanía plena y exclusiva en el espacio aéreo situado su territorio", conforme al artículo $1^{\circ}$ del convenio de Chicago sobre aviación civil internacional (2006, p. 2). Las infracciones a esta soberanía se consideran violación de espacio aéreo, que "concurre cuando éste se vuela sin someterse a las restricciones que el Estado detentador de su soberanía ha establecido legítimamente" (Mapelli, 2019, p. 12) haciendo "uso indebido de la aviación civil" (Mapelli, 2019, p. 13).

Por lo anterior, la responsabilidad por mantener íntegro el territorio $\mathrm{Na}$ cional, así como la soberanía e independencia, como aquellos documentos diseñados por la ONU sobre el uso de las armas por las autoridades encargadas de hacer cumplir la ley, genera suficientes argumentos legales y constitucionales para que los Estados determinen las acciones a tomar. El uso ilegal del espacio aéreo por parte del narcotráfico se constituye claramente en una violación. La preparación en este sentido de las tripulaciones siempre ha sido en pro de dar todas las garantías y respaldo a la hora de realizar las misiones de interceptación de aeronaves ilegales al espacio aéreo colombiano. El respeto por los derechos humanos siempre ha sido una norma de adopción de estas maniobras.

A la hora de hacer cumplir lo establecido y mantener la soberanía, el piloto y su aeronave, se convierten en el medio y modo de hacer la tarea impuesta a toda una institución. De hecho, la OACI a través del Anexo 10 al Convenio sobre Aviación Civil Internacional, Volumen I (2006), y por otra parte la Aerocivil han incorporado los mencionados procedimientos en los Reglamentos Aeronáuticos de Colombia (2020), como autoridades aeronáuticas mundial y nacional, tienen establecido los procedimientos para la interceptación de aeronaves civiles.

Además de lo anterior, la FAC, en cooperación con los Estados Unidos y acuerdos como el $\mathrm{ABD}$, ha fortalecido estos procesos, a fin de hacerlos más rigurosos, legales y con un fuerte componente disuasivo, además de humanitario; al prever y planificar todo un protocolo y ponerlo en marcha, en caso 
de disparar. Este proceso se debió, entre otras razones, a posibles casos de corrupción, por lo que los procedimientos debieron ser protocolizados en toda la institución.

Ahora bien, desde la cabina de un avión interceptor, recibir la burla del delincuente; bien fuera por gestos o por la frecuencia es algo difícil de describir por la impotencia de no poder hacer nada. La legitimidad, representada por un piloto y un avión haciendo la tarea de salvaguardar la integridad del espacio aéreo, se convirtió en un hecho que puso en riesgo la seguridad nacional.

La impotencia y la frustración para la Fuerza Aérea fueron grandes en los casos en los cuales no era posible realizar los procedimientos para interceptar una aeronave que posiblemente estuviese a las órdenes del tráfico aéreo ilegal. La burla del narcotráfico hacía que la rentabilidad de ese negocio estuviera por encima de la legalidad de un Estado. En ocasiones, sus aeronaves eran interceptadas 200 millas náuticas mar adentro y volaban hacia el continente con total tranquilidad, hasta el punto de suspender el aterrizaje y regresar hacia las aguas internacionales ${ }^{26}$, donde el alcance de los aviones de combate se restringía, por lo que para esas operaciones se lanzaban hasta cuatro aeronaves para la persecución, pero cómo se mencionó anteriormente sin ningún resultado.

Las operaciones que concluían en algunas ocasiones con el derribo de aeronaves ilegales permitían no solamente el mantener la soberanía, sino también neutralizar la distribución de narcóticos en otros países. Ante esto, y pocos años después, se comenzó a operar con plataformas de seguimiento de los Estados Unidos, con las cuales se establecieron procedimientos y directamente en las operaciones se fue ajustando la doctrina y protocolos, con la participación de la Defensa Aérea colombiana. Las aeronaves americanas eran Cessna Citation 550, cuyo call sign ${ }^{27}$ era Gaucho, y con estas empezó a verse un nuevo panorama menos complejo y con resultados. A partir de ese momento, las trazas podían perseguirse por los diferentes países por los que ilegalmente volaran, lo que permitía al Gaucho, establecer comunicación con la defensa aérea de cada país para actuar.

26 Esto ocasionalmente sucedía porque evidenciaban que al aterrizar serían capturados. Estos aviones estaban dotados con radios satelitales que les avisaban la situación para aterrizar en el destino planeado, por lo que era de esperar que la infiltración en muchos lugares era de seguro.

27 Indicativo de llamado. Es la forma de distinguir específicamente un vuelo militar. A cambio de utilizar el número de la matrícula del avión, se utiliza una designación de un nombre. En la doctrina y la mística se refiere a nombres qué tiene relación con la aviación como Halcón, Cóndor, etcétera. 
Pronto se generó información de los resultados de las capturas de estas tripulaciones ilegales en Centroamérica, así como del material incautado o los accidentes mar adentro o en las costas. Esto permitió seguir avanzando en la ejecución de operaciones con los Gauchos y miembros de la Aduana de los Estados Unidos. De igual forma, llegaron las fotografías y los vídeos de los resultados, en los que se especificaba en concreto algo más allá de la inteligencia que se conocía, como la matrícula de la aeronave, la procedencia, el destino y, en otras ocasiones, hasta los individuos capturados o los cuerpos recuperados tras los accidentes. También, se llegó a recibir reporte de qué tan bien estaba operando la Fuerza Aérea, su grado de efectividad, así como las medidas que debían tomarse para mejorar los resultados. Lo que se conoce como Lecciones Aprendidas ${ }^{28}$.

A bordo de los aviones interceptores, debían acatarse todas las instrucciones de rumbo, altura y velocidad a volar durante las maniobras. Se aprendió que debía repetirse la instrucción dada y su ejecución debía hacerse de manera oportuna, por cuanto unos pocos grados en altas velocidades hacia una interceptación podrían representar desvíos en la ruta y pérdida de tiempo y combustible innecesariamente tratando de resarcirse de los errores cometidos. Cuando era inminente la proximidad al objetivo del interceptor a la traza, y ante la necesidad de concentrar la atención en la maniobra, solamente se comunicaba por la frecuencia quién estaba en la pantalla radar guiando el interceptor hacia la traza. La tarea de este interceptor era la de ser preciso y oportuno ante las demandas de rumbo, altura y velocidad.

En el control cerrado de la interceptación, quién dirigía la maniobra de interceptación frente al radar llegaba a un nivel de precisión de decir "tiene el objetivo delante suyo" acompañado de la distancia en metros y la posterior solicitud de confirmación de ese contacto visual del piloto al objetivo. El piloto, al levantar la vista de sus instrumentos debía tener el objetivo a su alcance visual o, por lo menos, al alcance de las armas y debía, en este punto, reportar ese contacto visual. El vocablo Tally-ho ${ }^{29}$ era el llamado que el piloto

28 Las Lecciones Aprendidas han sido una de las bases para la generación de doctrina y el fortalecimiento de esta. La experiencia plasmada en estos documentos ha servido para medir el alcance efectivo de las aeronaves y Escuadrones de la Fuerza Aérea durante las distintas misiones y operaciones que desarrolla. Las lecciones aprendidas no son punitivas; por el contrario, plasman aquellos puntos donde hubo fortalezas qué mantenerse, así como las debilidades y fallas que deben subsanarse, con un plan de mejora que permita también medirse para evaluar el resultado obtenido.

29 Es una expresión de origen británico que proviene de la Segunda Guerra Mundial, que significa tener al enemigo o al objetivo a la vista. 
hacía cuando por sus propios ojos veían al objetivo y aun así continuaba el silencio de radio hasta la entrega de la traza al piloto, donde comenzaban los llamados o señales visuales para comunicarse con la aeronave infractora que estaba siendo interceptada ${ }^{30}$.

Anterior a estos procedimientos, la defensa aérea, que había detectado la traza con anterioridad al lanzamiento de los aviones, trabajaba con otras estaciones radar y aliados en la región para identificar la traza antes de declararla ilegal, para el envío de aviones para la interceptación. Cuando ya era considerada ilegal, y sigue siendo igual en la actualidad, se enviaban los aviones para interceptarla. Lo que seguía de ahí en adelante era buscar la manera de que esa traza aterrizara de acuerdo con las instrucciones para ser sometida a las autoridades en tierra o, por el contrario, hacer uso de las armas cuando estas aeronaves llegan al nivel de hostiles y los protocolos obligaban a autorización de disparo.

La primera misión de interceptación efectiva era motivo de júbilo para un piloto, por lo que representaba un éxito personal, profesional e institucional. Neutralizar una aeronave no solamente es la demostración de lealtad para con su misión, representa quizás salvar muchas vidas en peligro por culpa del narcotráfico. Las tripulaciones que obtenían estos resultados eran ocasionalmente motivo de asecho criminal, por lo que era necesario tomar todas las precauciones dentro y fuera de la institución.

Por todo lo anterior, la doctrina de la FAC tuvo mejoras significativas que a futuro se fueron evidenciando, gracias a los esfuerzos de pilotos, controladores de defensa aérea, tránsito aéreo y comandantes que, desde su posición, fueron aportando conocimientos y experiencia para la formulación y generación de la doctrina robusta que hoy en día posee la institución.

Posterior a los Gauchos y gracias a los resultados obtenidos, se fortaleció la confianza entre Colombia y EE. UU., lo cual permitió que en 2003 la FAC recibiera los primeros Cessna $560^{31}$ cuya misión específica era la de complementar y fortalecer los avances de las misiones contra el narcotráfico. Dichas aeronaves serían operadas directamente por personal de la Fuerza Aérea, cuyo entrenamiento duró varios meses antes de lanzar operaciones reales en el territorio nacional. Como parte de este proceso se crearon nuevos cargos a bordo de estas aeronaves, como el de Director de Misión (ODM); algo novedoso,

30 Este procedimiento sigue vigente hoy en día.
31 Con denominación militar de SR-560. 
que implicaba un salto enorme hacia el mando y control en la ejecución de operaciones directamente sobre las áreas donde estas se desarrollan.

Además, con la creación oficial de un Escuadrón de Defensa Aérea en las bases aéreas, llegó también una organización robusta tanto en los radares como en la lucha contra el narcotráfico. No demoró en escribirse una nueva doctrina que permitió reducir significativamente la cantidad de vuelos ilegales en el territorio colombiano. Las capacidades técnicas de las aeronaves adquiridas permitían hasta hacer registros de embarcaciones sobre el mar, así como ampliar las capacidades de visualización para la detección e identificación de las naves ilegales. Con los registros fílmicos y fotográficos, para las acciones legales tanto en Colombia como en otros países donde por cooperación entre Estados esta información se requiriera, se podía realizar la judicialización de los individuos y estructuras dedicas al tráfico de drogas.

En la actualidad, a bordo de los SR-560 vuela un personal altamente calificado y a partir del Director de Misión, todas las operaciones son altamente eficaces y eficientes, puesto que el ODM es quién dirige el escenario desde lo legal, operacional y doctrinario. Este cargo se distingue entre los demás, por cuanto el actuar de estas aeronaves y el de los interceptores es sometido en todo tiempo al acuerdo protocolizado con los Estados Unidos, así como los demás que existan con otros países; pero, sobre todo, enmarca a la FAC en la legalidad y la precisión de sus operaciones.

No quiere decir lo anterior, que en épocas anteriores a lo relatado esto no se hiciera. Por el contrario, la institución siempre ha actuado en el marco de la legalidad y respeto de los derechos humanos. Sin embargo, la misma legalidad exige permanentemente tomar medidas y ejecutar acciones que fortalezcan la institucionalidad a los ojos del derecho, la doctrina, el honor militar y la ética. Por lo anterior, neutralizar una aeronave ilegal, significa también lograr que ésta aterrice para su posterior captura. Este siempre ha sido un afán desde la cabina de los aviones interceptores, cuyos éxitos individuales siempre se han constituido en logros institucionales, en beneficio de la reducción de la oferta de estupefacientes disponibles en las calles.

\section{El efecto y el Impacto de Neutralizar Narcoterroristas}

En el desarrollo de operaciones militares, se hizo necesario fortalecer la ofensiva contra las estructuras en general. Una de ellas fue precisamente la del frente 16, bajo el mando de Tomás Medina Caracas conocido con el alias del "Negro Acacio". Él potenció en el oriente colombiano el negocio del narco- 
tráfico y de las armas, como fuente de financiamiento para las Farc, convirtiéndose en un objetivo a neutralizar ${ }^{32}$ por parte de las Fuerzas del Estado. Finalmente, el 2 de septiembre de 2007 y después de varias operaciones dirigidas contra este individuo, alias el Negro Acacio fue neutralizado durante la Operación "Sol naciente", llevada a cabo por la Fuerza Aérea Colombiana. De acuerdo con el análisis del señor General (RA) Flavio Ulloa:

El impacto de la neutralización de Acacio fue importante en lo operacional, en cuanto que afectó la capacidad de las Farc para comercializar la cocaína por el oriente del país hacia Venezuela, Surinam y Paraguay. Pero, antes de la neutralización de Acacio, en lo referente del control del espacio aéreo se había neutralizado el tráfico de cocaína por vía aérea. La recuperación del control territorial en el sur oriente del país, el incremento en la cobertura del espacio aéreo con los radares de Marandúa, San José del Guaviare, Leticia y Tres Esquinas; sumados a las operaciones con los AWACS de los Estados Unidos, además de una inteligencia regional mayormente eficaz y al despliegue de aviones de seguimiento e interceptores por parte de la FAC en diferentes Bases Aéreas, prácticamente eliminó las rutas en el sur oriente del país (el área del departamento del Vaupés y Amazonas, conocida como la Cabeza de Perro y en los departamentos de Meta y Vichada), obligando a los narcoterroristas a operar desde Venezuela con la anuencia de las autoridades de ese país.

Ahora bien, para las Farc fue un duro golpe la pérdida del terrorista Acacio, por el liderazgo que ejercía en el oriente del país a lo largo del rio Guaviare y por los contactos que tenía para el negocio, además de haber sido el primer cabecilla que perdían las Farc en un ataque aéreo contundente por parte de la FAC. Este ataque se vuelve emblemático por ser, tal vez, el primer ataque de alta precisión que se ejecuta y el inicio de una seguidilla de ataques que fueron poco a poco acabando con los cabecillas de este grupo narcoterrorista. Regionalmente tuvo efectos en cuanto que demostró que no había una guarida segura para las Farc, que permitió afinar el dúo Inteligencia-Operaciones y además que se empezó a utilizar HiTech en los ataques aéreos, convirtiendo la operación de ataque aéreo en el esfuerzo principal, en muchos de las operaciones conjuntas.

32 El concepto de neutralizar en el Derecho Operacional implica en su orden: someter a la justicia por entrega voluntaria, capturar y como último recurso dar de baja por efecto de operaciones militares, cuando las dos anteriores no se pueden cumplir, en especial, por la oposición consciente del criminal. 
Se puede decir que la guerra contra el narcotráfico hasta el año 2015 se estaba ganado. Una serie de acciones que desde lo estratégico se plasmaron en los diferentes planes de guerra, en lo operacional en los planes de campańa de las Fuerzas y desde lo táctico con las diferentes acciones en todo el país permitieron que la producción de cocaína en el país se haya reducido en más del 60\% y los cultivos ilícitos se hayan reducidos de 180.000 hectáreas a cerca de 45.000 hectáreas con un vector importante. La neutralización de capos y cabecillas, la contención de la capacidad criminal de las Farc, el Eln y los denominados grupos paramilitares, la aspersión aérea, la destrucción de laboratorios, la interdicción aérea, terrestre y marítima y la incautación de droga, entre otros, fueron elementos claves de la estrategia para derrotar el narcoterrorismo. Si los esfuerzos del país hubieran continuado hoy tal vez la historia que estamos viviendo sería otra y de seguro muchísimo mejor. (Entrevista estructurada, diciembre de 2019)

Este, como muchos otros efectos, se han venido dando a favor de la institucionalidad del Estado colombiano en la lucha, no solo contra el narcotráfico y sus delitos conexos, sino contra el terrorismo que en un momento de la historia del país logró afectar la tranquilidad de éste. En este sentido, la estrategia político-militar puso a prueba las capacidades como Estado de recomponer el orden democrático en el país. Sin duda alguna, la Fuerza Aérea Colombiana marcó la diferencia en esta tarea, al punto de negar y reducir estadísticamente el uso del espacio aéreo con fines ilegales, contribuyendo a la reducción de esta amenaza, además de operar conjunta y coordinadamente con toda la Fuerza Pública en esta importante misión.

\section{La Operación de la Fuerza Aérea más allá de sus Fronteras}

La estrategia con los aviones plataforma de vigilancia y seguimiento SR560, permitió no solamente ampliar la cobertura del espacio aéreo nacional, sino crear oportunidades concretas para reducir significativamente la operación del narcotráfico en Colombia. La combinación de aeronaves de reconocimiento y vigilancia con tecnología de punta y alta velocidad, junto a los aviones interceptores ha contribuido significativamente a alcanzar logros en materia de lucha contra el narcotráfico; no solamente en Colombia sí no en la región hemisférica con consecuencias globales. 
La operación de estas aeronaves junto con las armas ${ }^{33}$ se volvió eficaz en el escenario nacional, logrando alcanzar una reducción tan significativa de trazas por debajo del uno por ciento anual en el 2012 aproximadamente, a diferencia de quince años atrás, cuyos porcentajes eran del orden del 98\% de violación del espacio aéreo por tráficos ilegales.

Esta estrategia condujo a la creación de alianzas con los países alrededor de Colombia, así como en el Caribe, Centroamérica y Norteamérica, como las alcanzadas con los Estados Unidos, Honduras, Ecuador, Perú, Brasil y República Dominicana, entre otros. En estos acuerdos el marcado liderazgo del país y sus Fuerzas Militares y de Policía se evidenciaron en la exportación de capacidades más allá de las fronteras. Por ejemplo, la Fuerza Aérea Colombiana ha contribuido desde entonces a la reducción del narcotráfico; tanto en el propio país como en los mencionados anteriormente. En estos últimos, a pesar de persistir la amenaza, el intercambio operacional y hasta el permiso de sobrevuelo y uso de las bases militares para ampliar la cobertura de las aeronaves colombianas, ha significado un progreso de trascendencia mundial, donde países como los Estados Unidos han aportado a los propósitos y al liderazgo colombiano en la región.

Internamente, también se abrieron nuevas posibilidades para el despliegue operacional de manera rápida y oportuna; tanto de plataformas de vigilancia, así como de aviones de combate con el uso de bases militares y aeropuertos civiles. Esto último fue fundamental en la lucha contra el narcotráfico, por cuanto incrementó la respuesta de la Fuerza Aérea, en comparación con la década de 1980, marcó una gran diferencia y aumentó la credibilidad del Estado colombiano en la lucha contra las drogas.

Paralelamente, las Fuerzas terrestres y de superficie han cumplido la tarea en su jurisdicción territorial y son partícipes de los éxitos y logros alcanzados en la interdicción aérea y lucha contra el narcotráfico desde el aire, realizado por la Fuerza Aérea. Lo cual le ha permitido al país y al Gobierno colombiano mostrar una significativa reducción del tráfico de estupefacientes en los corredores desde el Pacífico y el Caribe hacia Centroamérica y los Estados Unidos. De hecho, es necesario resaltar que las capacidades de la FAC han contribuido a la operación conjunta en ambos mares junto con la Armada Nacional ${ }^{34}$. Estas dos instituciones han trabajado en la interceptación de lanchas rápidas denominadas "go-fast" y sumergibles, pertenecientes a las estructuras criminales, así como en la consolidación en el terreno, de acuerdo con el programa ABD.

33 En doctrina aérea, armas se refiere a aviones con capacidad de disparo.

34 Misiones ASTIM. 
Aunado a lo anterior, la integración de radares civiles y militares y la adquisición de otros más durante los últimos años han ampliado la capacidad de cobertura del espacio aéreo y la negación de este a vuelos ilegales sobre el territorio nacional. Complementando esta capacidad está el estricto cumplimiento de los acuerdos y protocolos en las misiones que concluyen con la neutralización de aeronaves ilegales, tanto en el aire como en tierra, ejecutados por aeronaves con capacidad de ataque de la FAC. Por lo anterior, es de resaltar que, en estos protocolos se incluyó desde hace muchos ańos la consideración de los derechos humanos en misiones que concluían en fase de derribo, a fin de garantizar el rescate de tripulantes del narcotráfico. Si bien ellos estaban delinquiendo, eran reconocidos dentro de los protocolos en los que prima el respeto por la vida, en los casos en los que fueren derribados o neutralizados.

Por otra parte, y retomando el caso de la exportación de conocimientos y capacidades a otros países, se puede citar el caso con Honduras. En 2011, algunos oficiales de la Fuerza Aérea Colombiana viajaron el país centroamericano para invitar a la Fuerza Aérea Hondureńa (FAH) a formar parte del plan contra el narcotráfico que venía desarrollando Colombia en la región. Fue interesante poder apreciar el entusiasmo y el profesionalismo con el cual los oficiales colombianos fueron recibidos, atendidos y escuchados por la contraparte hondureña, la cual se mostró entusiasta y deseosa de oficializar un acuerdo qué contribuyera a su país a reducir el narcotráfico.

En ese país, existe un departamento llamado Gracias a Dios, ubicado en el extremo oriental de Honduras, el cual ha representado históricamente el punto de convergencia del narcotráfico, desde y hacia el país. Su ubicación estratégica, además de su poca densidad poblacional y vulnerabilidad, lo ha convertido en un escenario propicio para las acciones ilegales del narcotráfico. $\mathrm{Al}$ poco tiempo de entrar en vigor el acuerdo de interdicción aérea entre Colombia y Honduras, comenzaron los formalismos de escribir los procedimientos qué llevarían a ambos países a fortalecer la lucha contra el narcotráfico, en el que incluiría, intercambio información, transferencia de entrenamiento y conocimientos, estandarización en procedimientos de interceptación, inteligencia, aerofotografía, así como de los permisos de sobrevuelo entre ambos países en persecución en caliente de aeronaves sospechosas.

Lo anterior, se hacía y se continúa haciendo dentro del marco de la legitimidad soberana y autónoma de cada país conforme a las leyes internas; es decir, respetando la mutua soberanía, pero trabajando mancomunadamente contra un enemigo común. De ahí que, una vez realizados los entrenamientos 
y la capacitación del personal hondureño, llegó el momento de evidenciar los alcances del acuerdo, que permitiría materializar resultados en beneficio común.

Con el equipo flir de las aeronaves, se pudo confirmar cómo las trazas que llegaban y posteriormente salían en el departamento Gracias a Dios eran recibidas y despachadas por un gran número de personas, quizá pobladores. Ellos acudían rápidamente a descargarlas una vez que llegaban para que la aeronave regresara al punto de salida, ubicado normalmente al oriente de Colombia.

Dado que se comenzaron a tener algunos resultados satisfactorios, se logró apoyo adicional como el de los EE. UU. para afrontar con mayores capacidades el narcotráfico en Honduras, lo que beneficiaba no solo a éste, sino también, eventualmente, a los demás acuerdos en la región. Es de resaltar a lo anterior, el incremento en las capacidades operacionales de la Fuerza Aérea Hondureña y un mejor alistamiento de aeronaves para combatir el crimen de las drogas, en su país y en la vecindad. De igual forma el Comando y Control en Honduras se vio fortalecido, integrándose con de los otros países, con los cuales se compartía información. Paralelamente, se mantenía comunicación permanente y se hacía transferencia de los tráficos ilegales volando entre Suramérica, el Caribe y Centroamérica.

Además de todo lo anterior, también hubo posibilidad de reducir considerablemente el tráfico ilegal marítimo hacia el mismo puerto en Honduras, donde las islas colombianas de San Andrés y Providencia, se consideraban puente logístico hacia el Caribe de embarcaciones que salían entre otros de puertos como Cartagena.

Detrás de toda esta infraestructura, ha estado la inteligencia humana y la técnica trabajando de forma sobresaliente, anticipando muchas veces los movimientos de estas estructuras criminales, así como de las redes de cooperación.

\section{Comando y Control: La Herramienta para un Comandante Informado en Tiempo Real}

El Concepto de Comando y Control desde entonces y como principio del Poder Aéreo (Fuerza Aérea Colombiana, 2019, p. 57), permite en la actualidad, mantener el mando, la autoridad y dirección de todas las operaciones aéreas, así como el seguimiento de éstas en cualquier parte del mundo. 
La Fuerza Aérea Colombiana fue desarrollando esta capacidad hasta establecer el direccionamiento y la supervisión de todas sus aeronaves en tiempo real donde quiera que se encuentren.

Anteriormente, este era un servicio asumido por un oficial de grado Coronel, con la concurrencia de un Capitán o de un Mayor, así como de algunos suboficiales que trabajan en las comunicaciones aeronáuticas. El control de las operaciones se ejercía a través de la información que las unidades aéreas reportan de la ejecución de éstas y, por lo tanto, el oficial del Centro de Operaciones Fuerza Aérea (COFA), simplemente tomaba y posteriormente hacía un resumen de lo sucedido al comandante de la Fuerza Aérea. Además, se hacía un control del alistamiento de aeronaves por bases aéreas, donde se podía apreciar su ubicación, como en el caso de los helicópteros desplegados por los AGAT.

Además, el oficial COFA no tenía la autoridad potestativa del comandante para dirigir en su nombre las operaciones aéreas. Por el contrario, se limitaba a conocerlas, hacer el resumen que era presentado al comandante de la Fuerza Aérea y enviado también al Comando General de las Fuerzas Militares. Inclusive este Coronel no necesariamente era piloto, un requisito indispensable que se tiene hoy en día para el direccionamiento de las operaciones aéreas.

Ante la dificultad de la información, la Fuerza Aérea debió hacer una reingeniería de las operaciones finalizando la década de 1990, para entrar en los primeros ańos del 2000 con una infraestructura tanto de instalaciones como organizacional compleja. El ideal era a partir de allí, alcanzar el nivel de velocidad de la información tan rápida como la velocidad de los aviones en el desarrollo de las operaciones, siendo esto una "solución del poder aéreo" (Hinote, 2009, p. 1), para las necesidades que enfrentaba el país, por cuanto las FFMM en su operación conjunta y coordinada con la Policía debían integrarse. Además, y en palabras del Mayor General (RA) Ramírez:

Finalizando la década de 1990 la Fuerza Aérea inició un proceso de transformación en el que participaron muchos oficiales. El comandante era el señor General Héctor Fabio Velasco y el oficial encargado de llevarnos al siglo XXI, el señor coronel Reynaldo Aragón Llanos (q.e.p.d.). Oficial de escuela, ingeniero, con una trayectoria muy brillante y con conceptos que para esa época se salían de la doctrina militar tradicional en las operaciones de orden público, así como contra el narcotráfico. Las zonas en donde 
operaba la guerrilla eran las mismas desde donde salía la droga. Era la narco guerrilla, y la droga les permitía crecer en personal y armas.

Con el señor coronel Aragón se encontraba trabajando el coronel Diego Suarez, oficial piloto del curso 55. Ellos consiguieron que en un salón trabajaran unidos los controladores de radares de la Dirección de Defensa Aérea (DIDAR), los controladores de las consolas de la Dirección de Comunicaciones (DICOM) y el personal de inteligencia, todos bajo la dirección de un oficial superior altamente entrenado en el arte y ciencia de la guerra. (Entrevista estructurada, diciembre de 2019)

Pronto, se logró que desde ese nuevo Centro de Comando y Control (CCOFA), se establecieran comunicaciones directas con las aeronaves en operación; así como, puente y enlace de éstas con las tropas de superficie lo que multiplicó las capacidades institucionales en la lucha contra el terrorismo y el narcotráfico.

A mediados del año 2000 se efectuó el nombramiento del Coronel Juan Carlos Mejía (citado en el presente capítulo como Mayor General) como el primer Director del CCOFA, al que le "correspondió implementar los procesos para que una Fuerza Aérea pequeńa pareciera bastante grande. Por esos ańos no tuvimos los equipos con los que actualmente contamos y la guerrilla se encontraba en ofensiva permanente" (Entrevista estructurada, diciembre de 2019).

El proceso de transformación fue difícil y complejo, pero contó con el respaldo del mando de la FAC. En palabras del Mayor General (RA) Ramírez Mejía:

Con los oficiales y suboficiales del nuevo CCOFA trabajamos para "reducir procesos y generar confianza”. El comienzo fue bastante difícil porque el CCOFA debía tomar aeronaves de diferentes unidades de la Fuerza y los comandantes de esas unidades se enojaban porque para ellos las aeronaves eran de ellos y no de la Fuerza. Al final todos entendimos que el CCOFA tenía una fotografía en tiempo real de todo lo que estaba sucediendo en Colombia. Se estaba afianzando el concepto de "mando centralizado y ejecución descentralizada" tan difícil de entender. Poco a poco los resultados se dieron. Debo resaltar el apoyo del alto mando al recién creado CCOFA. (Entrevista estructurada, diciembre de 2019)

Posteriormente, el cargo de Director del CCOFA fue entregado al señor Coronel Flavio Ulloa (citado en el presenta capítulo como General) quien 
también había sido asignado como Oficial de Enlace en JIATF-S en Key West. Debido a esa experiencia inter-agencial y el liderazgo del comando de la Fuerza se dio una transformación doctrinal hacia las operaciones combinadas contra el narcotráfico. Un salto estratégico que ha permitido desde entonces generar la sinergia de los países de la región en la lucha contra el problema mundial de las drogas. Debido a lo anterior y en palabras del Mayor General (RA) Ramírez, "gracias al excelente trabajo de nuestra Fuerza Aérea los americanos nos apoyaron en la arquitectura, diseño e implementación de un CCOFA completamente nuevo. No tenía nada que envidiarle al que [había] en Key West. Quedó simplemente espectacular” (2019).

Internamente, a partir de la culminación de la reestructuración que impulsó el Coronel Ulloa (mencionado en el presente capítulo como General) hacia una mejor "capacidad operacional e innovación, trabajando con sus subalternos y los comandantes de todas las unidades aéreas, se alcanzaron resultados excepcionales en la lucha contra el narcotráfico y la guerrilla", según palabras del Mayor General Ramírez (2019).

Por lo anteriormente descrito, el eslabón conductor en todo este proceso es el del comandante de Fuerza Aérea, quien por ser responsable en primera instancia de la lucha contra el narcotráfico ${ }^{35}$, debe estar siempre informado en tiempo real y con la capacidad de conducir sus operaciones a través de un Centro de Comando y Control. A partir de dicha información, él podrá tomar decisiones como en el caso del derribo de aeronaves ilegales, cuya potestad es exclusiva de su investidura como comandante. Es decir, el piloto de una aeronave recibe la autorización de disparo directamente del comandante a través del CCOFA. Esto permitió avanzar nueva y significativamente en la ejecución de las operaciones, cuando estas se ejecutaban en la selva o mar adentro, durante la persecución o seguimiento de las trazas ilegales. Todo lo anterior como parte del proceso de modernización y transformación a una Fuerza altamente operativa.

Ante la necesidad de saber en tiempo real lo que estaba sucediendo en las operaciones, el señor Mayor General (RA) Juan Carlos Ramírez comenta que:

El proceso de preparación de la Fuerza para enfrentar a un mismo enemigo se dio de manera ordenada. Las unidades aéreas iniciaron un proceso de mejoramiento de la capacidad a mediados 1990 para operar las 24

35 Es claro que el comandante de la Fuerza Aérea el responsable por mucho más. De lo que se está hablando aquí es tan solo una de esas responsabilidades como es la de combatir el tráfico ilegal de drogas en Colombia. 
horas del día, consiguiendo mantener en jaque a los narcoterroristas de las Farc y el Eln. El gobierno entendió que el factor decisivo para acabar la guerra se encontraba en la Fuerza Aérea. Empezando el año 2002 se inicia un plan de fortalecimiento con la adquisición de los aviones Supertucano y el mejoramiento de las capacidades de los helicópteros de combate. Se puede decir con mucho orgullo que las aeronaves dotaron la Fuerza, pero fueron sus hombres lo encargados de operarlas y alcanzar resultados operacionales que hoy son valorados por las mejores Fuerzas Aéreas del mundo. (Entrevista estructurada, diciembre de 2019)

Debido a lo anterior y dejando claras las responsabilidades, es de entender que se hizo deducible que los comandantes apliquen en todo momento su mejor juicio y criterio para dejar claras las relaciones críticas de mando para impulsar la razón de ser de las operaciones aéreas (Hinote, 2009, p. 58). Estas últimas deben estar por encima de todo y ser acordes con la constitución y la ley, dejando ver a través de ellas el respeto por el orden jurídico del Estado. Además, en un país como Colombia cuya condición de país en desarrollo y limitaciones presupuestales para adquirir o mantener volando una Fuerza Aérea, por ejemplo, es de suponer que "siempre que haya recursos limitados, debe haber algún grado de comando y control centralizado"36 (Hinote, 2009, p. 69).

Por lo tanto y como se ha venido explicando, "el control del poder aéreo [...] debe estar centralizado y el comando debe ejercerse a través del comandante de la Fuerza Aérea [con la] flexibilidad inherente y la capacidad de dar un golpe decisivo" 37 (Hinote, 2009, p. 58), al terrorismo, al crimen organizado trasnacional y las insurgencias que tanto daño han causado al pueblo colombiano, en cumplimiento de una misión asignada mediante la Constitución en su artículo 217 (Constitución Política de Colombia, 1991).

Cuando por razones propias de su cargo llega el momento decisivo de un comandante el de autorizar o no el derribo de una aeronave, es de entender que: I) el avión ilegal llegó a ser considerado hostil conforme a los protocolos del programa $\mathrm{ABD}$, II) este no se sujetó a las órdenes e instrucciones del piloto quien ayuda en el proceso de identificación e interceptación como una aeronave ilegal, y III) el sistema de defensa aérea nacional ha reconocido que éste se encuentra violando el espacio aéreo colombiano. Es muy posible que el

36 Traducción del autor.

37 Traducción del autor. 
comandante de la Fuerza Aérea haya vivido esta experiencia como piloto que es, por lo que sabe que debe tomar la mejor decisión en pro de mantener el orden constitucional y responder ante su piloto, su sistema de defensa aérea y su país por la soberanía e integridad del espacio aéreo.

Como se mencionó con anterioridad, para llegar a este nivel de decisión en manos de un comandante, ha habido la previa declaratoria de la aeronave de ilegal a hostil, se ha hecho caso omiso de órdenes e instrucciones del sistema de defensa aéreo y, se deduce que, se sabe del hecho de estar cometiendo una infracción y que asume de igual forma la responsabilidad de su accionar y las consecuencias del mismo, frente a la acción legítima de un Estado a través de sus Fuerzas Militares.

Hoy en día, el ABD ofrece todas las garantías posibles en derechos humanos, legalidad y doctrina, para hacer de la lucha contra el narcotráfico un programa exitoso para el país y el mundo. Sin embargo y a pesar del gran éxito del ABD, el Mayor General Ramírez afirma "que los comandantes hemos sido tímidos en mostrar esos resultados operacionales. Los americanos lo saben y por eso tienen un aprecio muy grande por la capacidad operacional de la Fuerza Aérea Colombiana" (Entrevista estructurada, diciembre de 2019).

Afortunadamente a esta estrategia se sumaron varios países del hemisferio como ya se había mencionado. Con el liderazgo de Colombia ha sido posible reducir a través de la legitimidad el problema de las drogas a nivel global, a pesar de que el enemigo ha llegado a ser poderoso económicamente, de alcances transnacionales y de convicciones por fuera la ética y la moral, las cuales son uno de los fundamentos por los que un país como Colombia tiene políticas de Estado de luchar permanentemente contra este flagelo.

Por lo anterior, cuando un comandante decide es porque el poder aéreo debe aplicarse directamente sobre objetivos ilegales, que concluyan en el resultado y los efectos operacionales y estratégicos que se esperan (Hinote, 2009, p. 69), a fin de contribuir desde la esquina de la Fuerza Pública, en el mantenimiento de un Estado social de derecho.

Estos antecedentes se constituyen, hoy en día, en una ventaja operacional enorme que la Fuerza Aérea le brinda al país, por cuanto la institución, a través de acuerdos multilaterales ha logrado afianzar su lucha contra el narcotráfico. El Centro de Comando y Control de la FAC es una estructura sólida, compleja y capaz de brindar la garantía del control centralizado de las operaciones que el comandante tiene en todo momento, así como la ejecución descentralizada de las mismas, conforme a las misiones de cada una de 
las unidades aéreas, la asignación estratégica de medios aéreos y las políticas de comando.

El comandante tiene a su alcance la libertad de la conducción de las operaciones a través de un blindaje doctrinario y legal, cuyo fundamento constitucional le permite la toma de decisiones en los momentos críticos, aún más en las misiones y operaciones contra el narcotráfico, las cuales requieren de una contundencia por parte del Estado para evitar en todo momento el accionar del crimen organizado transnacional. Como piloto, este comandante sabe a lo que se enfrenta; no sólo en su decisión, sino en cómo decir a ese piloto que se encuentra en una persecución, que haga lo que debe hacer cuando se le imparte una orden o decisión tomada, con la tranquilidad que siempre sabrá que ésta se ajusta al estricto orden de la legalidad, por lo cual, queda en evidencia, que el blindaje operacional se encuentra en toda la línea de mando, dirección, control y ejecución de las operaciones.

Finalmente, y desde la visión de un comandante, el General (RA) Edgar Lesmes, "se requiere estar monitoreando permanentemente las actividades de los narcos, mejorar nuestros sistemas de detección, inteligencia para detectar y destruir laboratorios, contrainteligencia para evitar ser infiltrados" (2019).

Además, y en lo referente al control de costas y su proyección en el escenario marítimo, así como la complejidad terrestre del territorio nacional, se hace necesario continuar el esfuerzo en la destrucción de cultivos, retomando con la fumigación aérea. Sin embargo, menciona el General que aun "es mucho lo que falta por hacer" (2019).

\section{Conclusiones}

En el caso puntual de la lucha contra el narcotráfico, la Fuerza Aérea Colombiana ha realizado desde la década de 1970 un esfuerzo monumental por adaptarse para hacerle frente a esta amenaza multidimensional. Como se ha intentado mostrar con este recuento histórico, en la medida en que la FAC, en varias ocasiones de la mano con otras instituciones de la Fuerza Pública e incluso con entidades de otros países, ha combatido al tráfico aéreo ilegal, las mafias has ajustado sus estrategias. Por ejemplo, trasladando sus operaciones o migrando sus cabecillas a países vecinos.

Por otro lado, con este recuento histórico se busca demostrar que, en la trayectoria de la FAC, se encuentran una serie de éxitos y también fracasos que le han permitido acumular una experiencia única en la lucha contra el 
tráfico aéreo ilegal. Experiencias que la han llevado a la consolidación de la doctrina sobre la que hoy enmarca su actuar. Antes del Air Bridge Denial (2003) y de las herramientas que este acuerdo ha provisto, como se ha tratado de detallar a lo largo del capítulo, la Fuerza Aérea ya realizaba esfuerzos por mantener la soberanía sobre el espacio aéreo colombiano y negar el puente aéreo a los vuelos ilegales. Hoy en día, la FAC se ha consolidado como un referente regional en la lucha contra el narcotráfico y en un exportador de conocimientos y experiencias a sus pares de otros países. Para llegar a este punto, se ha requerido de más de cuatro décadas de trabajo constante y de la labor de muchas personas que han entregado lo mejor de sí para salvaguardar la soberanía del espacio aéreo colombiano.

\section{Referencias}

Álvarez, C. y Zambrano, J. (2017). Globalización desviada: plataforma de convergencia criminal. En Y. Ramírez, C. Álvarez, D. Ruiz, N. Rosanía (Ed.), Escenarios y desafios de la seguridad multidimensional (pp. 249-306). Bogotá: Ediciones Escuela Superior de Guerra. https://doi. org/10.25062/9789585652835.04

Barrero D., y González Á. (2004). Ningún lugar está demasiado lejos. Asorfac, pp. 24-27.

Cuerpo de Generales y Almirantes en Retiro de las Fuerzas Militares. (2002). Esquilando al lobo. La dimensión desconocida del conflicto colombiano. Colombia: Panamericana Formas e Impresos S. A.

Del Río, C. M. (2015). Colombia siglo XX: Desde la guerra de los mil días hasta la elección de Alvaro Uribe. Bogotá: Pontificia Universidad Javeriana. https://doi.org/10.2307/j.ctv893gth

Fuerza Aérea Colombiana. (15 de diciembre de 2019). Hitos en la historia de Palanquero. Recuperado de https://www.fac.mil.co/cacom $1 \% 5 \mathrm{Chi}$ tos-en-la-historia-de-palanquero

Fuerza Aérea Colombiana. (2013). Manual doctrina básica aérea, espacial y ciberespacial Fuerza Aérea Colombiana FAC-0-8. Bogotá: Jefatura de Educación Aeronáutica.

Fuerza Aérea Colombiana. (6 de diciembre de 2019). Reseña Histórica CACOM-3. Recuperado de https://www.fac.mil.co/cacom3/Rese\%C3\%B1a\%20Hist\%C3\%B3rica\%20Cacom\%203 
Fuerza Aérea Colombiana. (s.f.). Reseña Histórica Cacom-6. Obtenido de Fuerza Aérea Colombiana: https://www.fac.mil.co/CACOM6/reseña-histórica-5

Fuerza Aérea Colombiana. (19 de diciembre de 2019). Reseña Histórica Gacar. Recuperado de https://www.fac.mil.co/gacar/Rese\%C3\%B1a\%20 Hist $\%$ C3\%B3rica\%20Gacar

González, F. (2006). Guerras civiles y construcción el Estado en el siglo XIX colombiano. Una propuesta de interpretación sobre su sentido político. Boletín de Historia y Antigüedades (832). Bogotá: Academia Colombiana de Historia.

González, F. E. (2014). Poder y violencia en Colombia. Bogotá: Editorial Pontificia Universidad Javeriana.

Hinote, C. (2009). Centralized Control and Decentralized Execution. A Catchphrase in crisis? Alabama: Air Force Research Institute.

ICAO. (2006). Convenio sobre Aviación Civil Internacional Doc 73 Q019 (novena ed.). Chicago: ICAO.

Mapelli, E. (23 de diciembre de 2019). Violación del espacio aéreo e intercepción de aeronaves. Obtenido de Boletín de información del Ministerio de Justicia de España: https:/www.mjusticia.gob.es/cs/ Satellite/Portal/1292344059520?blobheader=application\%2Fpdf\&blobheadername1 =Content-Disposition\&blobheadername2=EstudioDoctrinal\&blobheadervalue $1=$ attachment\%3B+filename\%3D1984_1355. pdf\&blobheadervalue2 $=1288776688281$

Morin, E. (2006). El método 6: ética. Madrid: Cátedra.

OEA. (2003). Declaración sobre Seguridad en las Américas. México: OEA. Disponible en http://www.oas.org/36AG/espanol/doc_referencia/DeclaracionMexico_Seguridad.pdf

Organización de Aviación Civil Internacional. (2006). Anexo 10 al Convenio sobre Aviación Civil Internacional. Telecomunicaciones Aeronáuticas (Volúmen I Radioayudas para la navegación) (Sexta ed.). Organización de Aviación Civil Internacional.

Pardo, R. (2004). La historia de las Guerras. Ediciones B Colombia S. A. República de Colombia. (1991). Constitución Política de Colombia. Recuperado de www.registraduria.gov.co/IMG/pdf/constitucio-politica-colombia-1991.pdf 
Unidad Administrativa Especial de Aeronáutica Civil. Oficina de Treansporte Aéreo - Grupo de Normas Aeronáuticas. (4 de junio de 2020). RAC 91. Recuperado de Reglamentos Aeronáuticos de Colombia: http:// www.aerocivil.gov.co/normatividad/RAC/RAC\%20\%2091\%20-\%20 Reglas\%20Generales\%20de\%20Vuelo\%20y\%20Operaci\%C3\%B3n. pdf

Villalobos, J. (1993). Historia de las Fuerzas Militares de Colombia. Fuerza Aérea Colombiana. Santa fé de Bogotá: Planeta Colombiana Editorial S. A. 